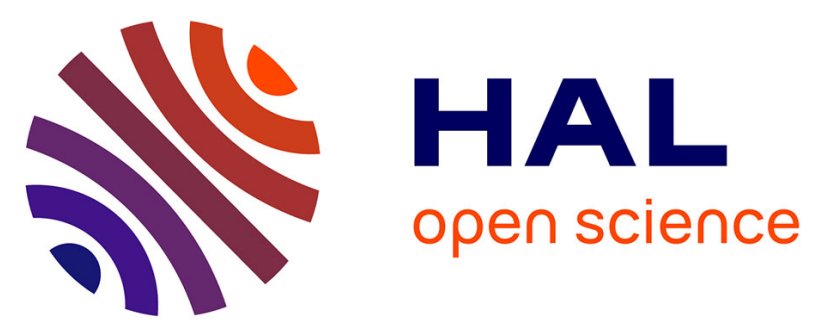

\title{
Safety assessment of Gram-negative bacteria associated with traditional French cheeses
}

\author{
M. Imran, N. Desmasures, M. Coton, Anne Le Fleche-Mateos, F. Irlinger, C. \\ Delbès-Paus, V. Stahl, M. Montel, Jean-Paul Vernoux
}

\section{- To cite this version:}

M. Imran, N. Desmasures, M. Coton, Anne Le Fleche-Mateos, F. Irlinger, et al.. Safety assessment of Gram-negative bacteria associated with traditional French cheeses. Food Microbiology, 2019, 79, pp.1-10. 10.1016/j.fm.2018.11.001 . hal-02086922

\section{HAL Id: hal-02086922}

https://hal-normandie-univ.archives-ouvertes.fr/hal-02086922

Submitted on 5 Jun 2020

HAL is a multi-disciplinary open access archive for the deposit and dissemination of scientific research documents, whether they are published or not. The documents may come from teaching and research institutions in France or abroad, or from public or private research centers.
L'archive ouverte pluridisciplinaire HAL, est destinée au dépôt et à la diffusion de documents scientifiques de niveau recherche, publiés ou non, émanant des établissements d'enseignement et de recherche français ou étrangers, des laboratoires publics ou privés.

\section{()ㅜ) $\Theta$}

Distributed under a Creative Commons Attribution - NoDerivatives| 4.0 International 
1 Safety assessment of Gram-negative bacteria associated with traditional French cheeses

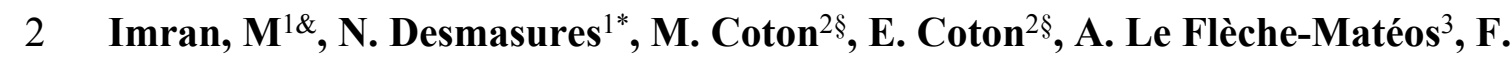

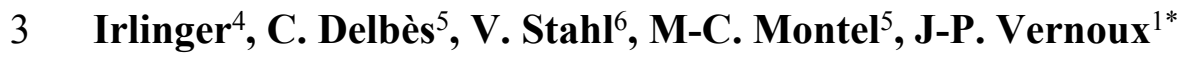

4

$5 \quad{ }^{1}$ Normandie Univ, UNICAEN, ABTE, 14000 Caen, France

$6 \quad{ }^{2}$ ADRIA Normandie, Bd du 13 juin 1944, 14310 Villers-Bocage, France

7 3'Unité Environnement et Risques Infectieux, Cellule d'Intervention Biologique d'Urgence,

8 Institut Pasteur, F-75724 Paris Cedex 15, France

$9{ }^{4}$ UMR GMPA, AgroParisTech, INRA, Université Paris-Saclay, 78850, Thiverval-Grignon, 10 France.

115 Université Clermont Auvergne, INRA, UMR 545 Fromage, Aurillac, France

$12 \quad{ }^{6}$ Aérial, 250 rue Laurent Fries, F-67412 Illkirch, France

13 Corresponding authors : jean-paul.vernoux@unicaen.fr and nathalie.desmasures@unicaen.fr

14 \& Present address: Department of Microbiology, Faculty of Biological Sciences, Quaid-i-Azam 15 University, Islamabad Pakistan.

$16 \S$ Present address: Univ Brest, Laboratoire Universitaire de Biodiversité et Ecologie 17 Microbienne, F-29280 Plouzané, France.

18

19 Running title: Safety of Gram-negative dairy isolates 


\section{ABSTRACT}

22

Twenty Gram-negative bacterial (GNB) strains were selected based on the biodiversity previously observed in French traditional cheeses and their safety was assessed considering various safety criteria. For the majority of tested GNB strains, only gastric stress at $\mathrm{pH} 2$ (vs $\mathrm{pH}$ 4) resulted in low survival and no regrowth after an additional simulated gastro-intestinal stress. Presence of milk was shown to be rarely protective. The majority of strains was resistant to human serum and had a low level of adherence to Caco-2 cells. When tested for virulence in Galleria mellonella larvae, GNB strains had LD 50 values similar to that of safe controls. However, four strains, Hafnia paralvei 920, Proteus sp. (close to P. hauseri) UCMA 3780, Providencia heimbachae GR4, and Morganella morganii 3A2A were highly toxic to the larvae, which suggests the presence of potential virulent factors in these strains. Noteworthy, to our knowledge, no foodborne intoxication or outbreak has been reported so far for any of the GNB belonging to the genera/species associated with the tested strains. The role of multiple dynamic interactions between cheese microbiota and GIT barriers could be key factors explaining safe consumption of the corresponding cheeses.

Keywords: Caco-2, Galleria mellonella, gastro-intestinal stress, human serum bactericidal assay, risk factors

\section{Introduction}

Cheese microbiota consists of diverse microorganisms, including yeasts, moulds, Grampositive and -negative bacteria (Dugat-Bony et al., 2016; Gori et al., 2013; Imran et al., 2012; Irlinger and Mounier, 2009; Larpin-Laborde et al., 2011; Martín and Coton, 2017; Mounier et al., 2009, 2017; Wolfe et al., 2014). Microbial community diversity is important during cheese making as it is associated with cheese sensorial quality but can also contribute to ensure microbiological control and safety (Delbes et al., 2007; Delbès-Paus et al., 2012; Irlinger and 
Mounier, 2009). While literature data are abundant concerning yeasts/molds and Gram-positive bacteria (GPB) in cheese, Gram-negative bacteria (GNB) have been seldomly studied. However, a wide diversity of GNB, found at relatively high levels in raw milk (around 3 to 4 Log CFU/mL), has been reported (Desmasures et al., 1997; Frétin et al., 2018; Kable et al., 2016). GNB usually represent from 18 to $60 \%$ of the bacteria isolated from the surface of European smear cheeses (Larpin-Laborde et al., 2011; Maoz et al., 2003; Montel et al., 2014; Mounier et al., 2005, 2017; Wolfe et al., 2014). Most of the microorganisms found in cheese originate from raw milk, (animal, milking machine, environment /air) (Desmasures et al., 1997; Frétin et al., 2018), processing steps, plant, transportation equipment, labor and cheese factory sources (Mounier et al., 2006). GNB present on the surface of the ripened soft cheese mainly belong to Enterobacteriaceae, Moraxellaceae, Pseudoalteromonadaceae, Pseudomonadaceae, Sphingobacteriaceae and Vibrionaceae families (Bockelmann et al., 2005; Chaves-Lopez et al., 2006; Maoz et al., 2003; Mounier et al., 2005; Tornadijo et al., 1993). Previous work, done between 2008 and 2010 aimed at studying GNB associated with French milk and corresponding cheeses. The obtained 173 isolates corresponded to at least 26 genera and 68 species, including potential new species. Pseudomonas, Chryseobacterium, Enterobacter, and Stenotrophomonas were the most frequent genera found in cheese core and milk samples, while Proteus, Psychrobacter, Halomonas and Pseudomonas were the most frequent genera isolated from cheese surface (Coton et al., 2012).

Some GNB species found in cheese were reported to include some non-foodborne strains associated with clinical cases (Delbès-Paus et al., 2012). Criteria to classify bacteria as human pathogens or non-pathogens depends on the presence or absence of virulence factors. Survival during gastro intestinal transit and then adhesion to enterocyte cell surfaces is often the first step in establishing potential bacterial disease. For extracellular pathogens, adhesion is a means to withstand mechanical cleaning. For intracellular pathogens, adhesion is often a 
prerequisite for invasion (dos Santos et al., 2015). The human adenocarcinoma cell line Caco-

73 2 , isolated from an adult human colon, which expresses several markers characteristic of normal small villi cells (Fogh et al., 1977; Pinto et al., 1983) has been extensively used to study bacterial adhesion mechanisms for pathogens and probiotic strains (Greene and Klaenhammer, 1994).

Another barrier in the human body against invading pathogens is the action of serum through a series of serum proteins interacting in a regulated sequential manner that eventually leads to bacterial death due to either lysis or opsonisation (Morgan et al., 2000). Furthermore, the safety status evaluation of a given microorganism must also be assessed by its actual pathogenicity on an animal model. Mammals have been used for a long time to evaluate microbial pathogen virulence but it is time consuming, labor intensive, and expensive in terms of purchasing animals, feeding, and housing. An alternative option is the use of an insect model (Kavanagh and Reeves, 2004) because the innate immune responses are similar. A useful model is Galleria mellonella (wax moth) larvae (Ramarao et al., 2012). It has been used to evaluate the pathogenicity of various GNB such as Proteus mirabilis (Morton et al., 1987), Francisella tularensis (Aperis et al., 2007), Yersinia pseudotuberculosis (Champion et al., 2009), Stenotrophomonas maltophilia (Nicoletti et al., 2011) and Escherichia coli (Walters and Ratcliffe, 1983). For example, Pseudomonas aeruginosa virulence or that of Bacillus thuringiensis and Bacillus cereus were correlated in Galleria larvae and in mice (Jander et al., 2000; Salamitou et al., 2000). In fact, the virulence of many pathogens is similar in wax moth larvae and mammals, including Humans (Desbois and Coote, 2012).

The present study is a continuation of the previous work reported by Coton et al., (2012) 
survival in serum conditions and pathogenicity on insect larvae, were assessed to provide a

98 more comprehensive view about the safety these GNB isolates.

\section{Materials and methods}

103 raw milk or milk, cheese core or cheese surface representative of the main identified genera and

104 of different safety status (evaluated according to low or high antibiotic resistance and biogenic

118 Infusion agar (BHA, AES, France). For each strain, three plates were inoculated

119 simultaneously: two plates were incubated at $37^{\circ} \mathrm{C}$ respectively under aerobic and anaerobic

120 (AnaeroGen Pack, Oxoid, France) conditions for 14 days and one plate was incubated at $25^{\circ} \mathrm{C}$

121 under aerobic conditions. If growth appeared as expected in aerobiosis on at least one plate and 
122 for one temperature, results for growth/no growth at $37^{\circ} \mathrm{C}$ under anaerobic conditions were 123 considered.

124

\subsection{Gastric and gastro-intestinal media and stress simulation}

For gastro-intestinal stress simulation tests, bacterial strains were first precultured in $\mathrm{J}$ 128 7.2) (Clavel et al., 2004) and incubated at $25^{\circ} \mathrm{C}$ for $24 \mathrm{~h}$ with shaking to obtain optimal growth.

143 gastric stress simulation at $0,1.5$ and $3 \mathrm{~h}$. For all enumerations, bacteria were plated on J agar (JA) (JB supplemented with $15 \mathrm{~g} / \mathrm{L}$ agar), incubated at $25^{\circ} \mathrm{C}$ under aerobic conditions for $24 \mathrm{~h}$.

Simulated gastric medium (GM) was prepared by adding one volume of a sterile (autoclaved $121^{\circ} \mathrm{C}, 15 \mathrm{~min}$ ) gastric electrolyte solution (Gänzle et al., 1999) containing $4.8 \mathrm{~g} / \mathrm{L}$ $\mathrm{NaCl}, 1.56 \mathrm{~g} / \mathrm{L} \mathrm{NaHCO} 3,2.2 \mathrm{~g} / \mathrm{L} \mathrm{KCl}$ and $0.22 \mathrm{~g} / \mathrm{L} \mathrm{CaCl}_{2}$ to one volume of JB (GM-JB; autoclaved $\left.121^{\circ} \mathrm{C}, 15 \mathrm{~min}\right)$ or milk medium $(100 \mathrm{~g} / \mathrm{L}$ of half-skim milk powder; autoclaved $100^{\circ} \mathrm{C}, 30 \mathrm{~min}$ ) (GM-milk (Clavel et al., 2004, 2007). After sterilization, the $\mathrm{pH}$ of the GM-JB or GM-milk media were adjusted to 2 or 4 with sterile $1 \mathrm{~N} \mathrm{HCl}$ to simulate the acidic environment of human gastric fluids. Finally, media were supplemented with 500U/1 of a filter sterilized $(0.22 \mu \mathrm{m})$ pepsin (gastric juice enzyme) solution prepared in water (P6887; SigmaAldrich, France) just before use.

For gastric stress experiments, GM-JB and GM-milk media were inoculated with each strain at initial populations of $\mathrm{N}_{0}=1.10^{6} \mathrm{CFU} / \mathrm{mL}$ and incubated at $37^{\circ} \mathrm{C}$ with shaking $(160$ 
147 obtain the simulated gastrointestinal medium (GIM). These two media were named GIM-JB

148 and GIM-milk. Bovine bile (B3883, Sigma-Aldrich, France) was added or not at $1.5 \mathrm{~g} / \mathrm{L}$.

149 Incubation in GIM-JB and GIM-milk was done at $37^{\circ} \mathrm{C}$ without shaking for $28 \mathrm{~h}$ to simulate

150 the gastro-intestinal stress. Numerations were carried out at different time intervals: $0,1.5,3$, 1515,21 and $28 \mathrm{~h}$.

152 Bacterial survival was expressed as the $\log \left(\mathrm{N} / \mathrm{N}_{0}\right)$ where $\mathrm{N}_{0}$ is the initial population that was 153 adjusted to $10^{6} \mathrm{CFU} / \mathrm{ml}$ and $\mathrm{N}$ is the number of $\mathrm{CFU} / \mathrm{mL}$ obtained after $3 \mathrm{~h}$ (gastric stress) or $15431 \mathrm{~h}$ (gastro-intestinal stress). The two-fold dilution, due to changing the gastric stress medium 155 to the gastro-intestinal stress medium, was taken into account.

156 All numerations were done by serially diluting bacterial suspensions in Trytone Salt (TS) 157 diluent and plating on JA medium with a spiral system (Intersciences, France). Cell 158 concentrations were expressed as $\mathrm{CFU} / \mathrm{mL}$.

\subsection{Tissue culture and in vitro adhesion assay}

161 The strains were tested for their adhesion ability in vitro on epithelial intestinal cells (Caco-2:

162 colon adenocarcinoma human, ATCC, USA, Lot\# 4129634). The intestinal cells were routinely 163 cultured and used as already described (Tareb et al., 2013). Cultures were used at post164 confluence after 15 days of culture (differentiated cells). To determine the number of Caco-2 165 cells in a monolayer, cells were detached for 2 min with Splittix and Splitstop (Bio Media) at 166 ambient temperature and counted using a Thoma cell. Three non-pathogenic control strains 167 were used: E. coli Nissle 1917 (obtained from Dr. Ulrich Sonnerborn from Ardeypharm, 168 Germany $\mathrm{GmbH}$ ), with a long history of safe use as a probiotic and large body of acquired 169 knowledge (EFSA Panel on Biological Hazards (BIOHAZ), 2014; Wassenaar, 2016), E. coli $170 \mathrm{~K} 12$ (ATCC 10798) and Lactobacillus rhamnosus GG strain. In addition, another control was 171 used: Escherichia coli O157: H7 C267 (stx-, eae+), this strain is a shiga toxin negative mutant 
172 (stx1- and stx2-) which has kept the gamma-intimin (adherence protein) producing gene $173(e a e A+)($ Vernozy-Rozand et al., 2000). Bacterial strains were cultured in TSB-YE incubated 174 at $37^{\circ} \mathrm{C}$ or $25^{\circ} \mathrm{C}$ (for strains unable to grow at $37^{\circ} \mathrm{C}$ ) for $24 \mathrm{~h}$ under shaking $(120 \mathrm{rpm}$ ) and then 175 washed twice with PBS. Concentrations were adjusted to $2 \times 10^{8}$ cells $/ \mathrm{mL}$ and cells were labeled 176 with $0.2 \%$ aqueous solution of 4', 6-diamidino-2-phenylindole (DAPI, Sigma) by incubating 177 for $15 \mathrm{~min}$. Three washing steps were performed with PBS (0.01 M, pH 7.4) to remove excess 178 unbound DAPI, then cells were suspended in $0.2 \mathrm{~mL}$ Dulbecco's Modified Eagle Medium 179 (DMEM) without antibiotics and put into contact with Caco-2 cells at a final concentration of $10^{7}$ per $7 \times 10^{4}$ Caco-2 cells for $2 \mathrm{~h}$ under standard Caco-2 growing conditions (incubation at $37^{\circ} \mathrm{C}, 5 \% \mathrm{CO}_{2}, 95 \%$ humidity). Not adherent bacterial cells were removed by three washing 182 steps with PBS solution and cell fixation was performed using a $3.7 \%(\mathrm{w} / \mathrm{v})$ solution of 183 formaldehyde in PBS.

Enumeration of adherent bacteria was performed using an epifluoresence microscope.

185 Results were determined as an average of ten observations per assay. Adhesion was calculated 186 by enumerating the adhered bacterial cells in 10 microscopic fields for each strain and was 187 expressed as the average number of adhered bacterial cells per 100 Caco- 2 cells. For selected 188 strains, validation of bacterial adhesion was performed by using electron microscopy as 189 routinely done (Tareb et al., 2013).

\subsection{Human serum bactericidal assay}

192 To determine the sensitivity of GNB strains to human serum, human serum type male, 193 blood group: AB, HIV negative (Biowest, Nauille-France) was used. The bacterial strains were 194 cultivated overnight in TSB under shaking at 30 or $37^{\circ} \mathrm{C}$, depending on the strain. GNB strains 195 and negative/positive control strains (see below) were added to 50\% human serum solution to 196 obtain the initial cell density of $10^{5}$ cells per mL (Jankowski et al., 1996). Each mixture was 
separated in two aliquots, one was plated onto Tryptic Soy Agar (TSA) in Petri plate and was

198 incubated at 30 or $37^{\circ} \mathrm{C}$ according to the tested strain. The other one was placed in a water bath

199 for 3 hours at $37^{\circ} \mathrm{C}$ then plated onto TSA and incubated at 30 or $37^{\circ} \mathrm{C}$. The results were 0\% mortality were found (Lorke, 1983). validated by using Hafnia alvei 56.85 (resistant strain) as a positive control and Hafnia alvei 31.86 (sensitive strain) as a negative control (Jankowski et al., 1996).

\subsection{Pathogenicity evaluation:}

Galleria mellonella larvae were grown in medium containing 50.6\% wheat flour, 19\% honey, 19\% glycerol, $7.7 \%$ brewer's yeast and 3.7\% bee hive wax. All bacterial strains were grown as mentioned above, washed three times and cell concentrations were adjusted to $\sim 10^{10}$ cells/mL of PBS by optical density (OD $600 \mathrm{~nm}$ ) determination using pre-enumeration data for each strain. The two non-pathogenic Escherichia coli K12 and E. coli Nissle 1917 strains were used as safe controls. Additionally, as above, E. coli C267, O157: H7 (stx1-, stx2-, eaeA+) was also used because of the presence of an adherence protein (intimin coding gene eaeA). Galleria mellonella larvae, in groups of ten, were inoculated by injection into the haemocoel through the last pro-leg by using a sterile syringe (Needle: $0.33 \mathrm{x} 12 \mathrm{~mm} ; 0.3 \mathrm{~mL}$ U-100 insulin- TERUMO, Belgium) with a needle diameter of $0.33 \mathrm{~mm}$. Ten $\mu 1$ of sterile PBS (negative control) and 10 


\subsection{Statistical analysis}

223 Principal Component Analysis (PCA) using Pearson correlation (n) method to determine the 224 correlation between different variables was carried out by using XLSTAT 2014.5.03 program.

\section{Results and Discussion}

3.1 Growth Assessment of Gram negative bacterial species in different conditions related to the human gastro intestinal tract (GIT) environment

\subsubsection{Growth at $37^{\circ} \mathrm{C}$}

The ability to grow at $37^{\circ} \mathrm{C}$ under anaerobic conditions was first tested on Petri dishes as it is an easy way to screen bacteria in order to evaluate their potential to survive in human body temperature conditions. All strains grew at $25^{\circ} \mathrm{C}$ in aerobic conditions. At $37^{\circ} \mathrm{C}$ under aerobic conditions, only one strain Alcaligenes faecalis 904 did not grow. Twelve out of the 20 selected isolates $(60 \%)$ were able to grow at $37^{\circ} \mathrm{C}$ under anaerobic conditions (Table 1). As expected most of the tested Enterobacteriaceae (e.g. Citrobacter, Klebsiella, Morganella, Proteus or Hafnia alvei) were able to grow in these conditions, which is in accordance with their general physiological characteristics. Surprisingly, some Enterobacteriaceae (namely, Hafnia paralvei 920, Proteus sp UCMA 3779 (close to P. hauseri)) did not grow in these conditions. Growth of Pseudomonas sp. depended on the considered strain, and it was positive for Pseudomonas putida CV30.6 and negative for Pseudomonas putida VRBG37.3. 


\subsubsection{Gastric and gastrointestinal stress simulation}

To get closer to in vivo conditons, survival of 20 GNB dairy strains was evaluated 249 successively in simulated gastric fluids and gastrointestinal stress environments over time, in 250 the presence or absence of milk (to mimic ingestion of a dairy product), in vitro. For all strains, 251 growth data after $3 \mathrm{~h}$ gastric stress and $28 \mathrm{~h}$ gastrointestinal stress at $37^{\circ} \mathrm{C}$ were plotted together 252 and are presented in Table 2. Additionally, changes in counts for four strains representative of 253 the observed behaviours during the $31 \mathrm{~h}$ gastric and gastrointestinal stress simulation are 254 presented in Figures 1 A to D.

The effects of in vitro simulated gastric stress were assessed over a $3 \mathrm{~h}$ period, for the

20 selected GNB dairy isolates, in the presence of gastric juices (containing $500 \mathrm{U} / 1$ pepsin), 257 and at $\mathrm{pH} 2$ and $\mathrm{pH}$ 4, supplemented or not with milk. A good survival, corresponding to stable 258 or increased population counts, was observed for the majority of the 20 GNB isolates in gastric 259 juices initially adjusted to $\mathrm{pH}$, both in the presence or absence of milk, except for Alcaligenes 260 faecalis 904 and to a lesser extent for Pseudomonas putida VRBG37.3, and in GM-milk for 261 Halomonas venusta/alkaliphila/hydrothermas 4C1A and Sphingobacterium sp. PCAi F2.5 262 (Table 2). At pH 2.0 in the absence of milk, a decrease in survival for the majority (14 strains) 263 of strains was reported. Six strains actually grew or presented relatively stable populations in 264 these conditions: Acinetobacter sp. PCAi E6.10, Hafnia paralvei 920, Halomonas 265 venusta/alkaliphila/hydrothermas 4C1A (Figure 1A), Pantoea agglomerans Q6.3, Providencia 266 heimbachae GR4, and Sphingobacterium faecium F2.5. In the presence of milk, a decrease in 267 survival was also mainly observed for 13 strains. In these conditions, populations remained 268 relatively stable for only 7 strains $(\log (\mathrm{N} / \mathrm{N} 0)>-0.5)$ : Chryseobacterium bovis Pi18 (Figure 269 1B), Hafnia paralvei 920, Halomonas venusta/alkaliphila/hydrothermalis 4C1A (Figure 1A), 270 Halomonas sp. B39, Morganella morganii 3A2A, Providencia heimbachae GR4 and 271 Pseudomonas putida CV30.6 (Table 2). 
These results showed that under simulated gastric stress conditions (no bile salts added), 273 pH 2 had a different effect on growth than $\mathrm{pH}$ 4; presence of milk had only a slight impact on 274 growth for both tested $\mathrm{pH}$ values.

\section{5}

The effects of an additional $28 \mathrm{~h}$ simulated gastrointestinal stress (with or without $1.5 \mathrm{~g} / \mathrm{L}$ bile salts) after $3 \mathrm{~h}$ gastric stress treatment, at $\mathrm{pH} 2$ or $\mathrm{pH} 4$, on the viability of the 20 GNB 277 dairy isolates was then evaluated at neutral $\mathrm{pH}(\mathrm{pH}$ 6.5). In all the tested conditions, no or low 278 survival was observed for Alcaligenes faecalis 904 while two other strains exhibited good 279 survival in all conditions as observed by an increase in population counts or re-growth during 280 the simulated stress (i.e. Halomonas sp B39, Panteoa agglomerans PCA Q6.3). Surprisingly, 281 bile salts (studied concentration was $1.5 \mathrm{~g} / \mathrm{L}$ ), that are normally encountered during 282 gastrointestinal stress, did not modify strain survival or had only slight effects when compared 283 to the same conditions without bile salts (for example among others, Chryseobacterium bovis 284 Pi18 (Figure 1B) or Pseudomonas putida VRBG 37.3).

285 No or low survival of a large number of strains was observed after a $\mathrm{pH} 2.0$ gastric fluids 286 treatment regardless of the conditions encountered in the simulated gastrointestinal tract. No or 287 low survival was observed for 7 strains at $\mathrm{pH} 2$, contrary to a high growth observed at $\mathrm{pH} 4$ for 288 these strains. This was the case for Hafnia alvei (Biogroup 1) B16, Proteus sp. (close to P. 289 hauseri) UCMA 3779 (Figure 1C), Pseudomonas putida CV 30.6, Pseudomonas stutzeri 290 UCMA 3883, and Psychrobacter celer 91. Survival in the simulated gastrointestinal tract 291 containing milk was better for some strains: Hafnia paralvei 920, Halomonas sp. B39 and 292 Proteus sp. (close to P. hauseri) UCMA 3780, suggesting a protective effect on the overall 293 survival in GIM-media of these dairy isolates.

These results showed that the determinant role of initial $\mathrm{pH}$ persisted while bile salts 295 concentration had a negligible effect on growth; the addition of milk rarely showed a protective 296 survival effect for the tested GNB strains at both pHs after the total of $31 \mathrm{~h}$ of incubation. 
Noteworthy, the simulated TGI stress conditions could also potentially lead to a viable but non-

298 culturable state for some cells and under some conditions, thus potentially underestimating 299 viable cell counts. This state has been previously observed for some foodborne pathogens in environmentally limiting conditions during food processing and conservation such as drastic temperatures or the use of preservatives (Zhao et al, 2017).

The protective survival effect of food in gastrointestinal simulated media has already been observed for Bacillus cereus (milk media) (Clavel et al., 2007), Bifidobacterium (soymilk) (Shimakawa et al., 2003) and Lactobacillus curvatus (meat based medium) (Gänzle et al., 1999) and is often linked to food components such as proteins and fats. Additionally, in the intestinal tract, bile reacts with cell membrane phospholipids and proteins and disrupts cellular homeostasis (Begley et al., 2005). However, in this study, the presence of bile salts in the intestinal media only had an effect on a limited number of strains and low survival was rather due to the acidic environment encountered in the gastric fluids simulation before the gastrointestinal stress. High variability in bile salt tolerance has also been previously observed for GPB such as lactic acid bacteria and Listeria monocytogenes (Begley et al., 2005; Chateau et al., 1994; Hyronimus et al., 2000). Finally, some species including those belonging to Chryseobacterium sp., Proteus sp., Halomonas sp. and Psychrobacter sp., recently identified as corresponding to the most frequent surface and/or core genera of French dairy products (cheeses and milk, (Dugat-Bony et al., 2016)) did not survive well in the simulated gastric and gastrointestinal media used in this study.

\subsection{Adhesion analyses}

The observed adhesion capacities are presented in Table 3 as a mean of two biological replicates. Results for all tested strains varied from 5 to 363 bacterial cells per 100 Caco-2 cells. Value for attachment of Lactobacillus rhamnosus GG to Caco-2 cells were similar to that 
previously published (Gopal et al., 2001), thus confirming the validity of the present results.

323 The results for adherence of the two Gram negative species used as safe control strains were 324 low (<100 cells) as well for the control E. coli O157: H7 C267 (stx1-, stx2-, eae+) and twelve 325 other strains. The other remaining eight strains exhibited attachment $>100$ cells and the most adherent strain was Halomonas venusta/alkaliphila/hydrothermalis 4C1A with 363 cells per 100 Caco-2 cells, followed by 200, 152, 145, 141, 138, 114, 100 microbial units for Alcaligenes faecalis 904, Proteus sp (close to P. hauseri) UCMA 3779, Psychrobacter celer 91, Pseudomonas group putida VRBG 37.3, Klebsiella oxytoca 927, Pseudomonas stutzeri UCMA 3883 and Citrobacter freundii UCMA 4217, respectively. Adherence is a clue for probiotic potential but is also the first step leading to potential cytotoxicity (dos Santos et al., 2015; Pavlov et al., 2004; Pogačar et al., 2015). In the present study, adhesion capacity was overall low for most of the tested strains and it was lower than previously tested strains of the same species present in drinking water (Pavlov et al., 2004). The low level of adherence was also confirmed by scanning electron microscopy (data not shown).

\subsection{Bactericidal effect of human serum}

The strains were described as sensitive or resistant to human serum after incubation in the presence of $50 \%$ human serum for three hours in comparison to known resistant and sensitive control strains of Hafnia alvei (e.g. in Table 4). Only 5 out of the 20 strain subsets were sensitive, namely Halomonas B39, Halomonas venusta/alkaliphila/hydrothermalis 4C1A, Pseudomonas group putida VRBG 37.3, Psychrobacter celer 91 and Sphingobacterium sp. (close S. faecium) PCAi F2.5 (Table 3). Most of the studied strains showed resistance against human serum as previously reported for GNB like Acinetobacter sp. (King et al., 2009). Serum resistance is often related to capsules or lipopolysaccharides which can protect the bacteria from entrance of the bactericidal compounds, but lipopolysaccharides are not solely responsible for resistance (Wand et al., 2013). The complement system is a series of serum proteins interacting 
347 in a regulated sequence that could lead to bacterial cell death (Morgan et al., 2000). The

348 resistance mechanism could be due to a bacterial surface protein which binds the human factor

$349 \mathrm{H}(\mathrm{FH})$, and thereby inhibits complement deposition on the bacterial surface (Quin et al., 2006).

3503.4 Virulence of bacteria to Galleria mellonella

The 20 selected GNB and four control strains were tested for virulence in G. mellonella

352 (Table 3). All PBS-injected control larvae grew until the moth stage. Control strains, E. coli 353 Nissle 1917, E. coli K12 ATCC 10798, and Lactobacillus rhamnosus GG had LD 50 from 354 around $10^{7}$ to $>10^{8}$, respectively. This range was considered as the reference non-toxic range, 355 since it was obtained for the three safe control strains. Thirteen GNB strains showed no 356 virulence score within this range. Among them Hafnia alvei (biogroup 1) B16 was found safe 357 which is reassuring as strains from this species are used as commercial ripening cultures for 358 many cheeses (Irlinger et al., 2012). Three strains, including K. oxytoca 927, P. stutzeri UCMA 359 3883, Sphingobacterium sp (close to S. faecium) PCAi F2.5 had intermediate LD 50 around 6.5 $36010^{6}$ as observed for $E$. coli $\mathrm{O} 157: \mathrm{H} 7$ (stx1-, stx2-, eae+) C267 wich was used as a control. Two 361 strains, H. paralvei 920 and Proteus sp (close to P. hauseri) UCMA 3780, were toxic to larvae 362 with a lower LD 50 around $10^{5}$. Two other strains were even more virulent, with LD50 value 363 lower than $10^{4}$, and corresponded to Providencia heimbachae GR4 and Morganella morganii 364 3A2A.

365 Assuming that G. mellonella larvae injection experiments are commonly used to detect 366 bacterial strains presenting virulence factors and that the virulence of many pathogens is similar 367 in wax moth larvae and mammals, including Humans (Desbois and Coote, 2012), it was 368 deduced that only few strains contained efficient virulent factors and could act as direct or 369 indirect pathogens. In the literature, a recent study showed that Galleria mellonella can also 370 provide significant insights into virulence mechanisms and that this can be applied to the study 371 of opportunistic human pathogens (Wand et al., 2013). Virulence clearly depended here on the 
considered strain but not on its origin as two Proteus sp. (close to P. hauseri) strains, 3779 and

373 3780, having the same origin, were very different in their virulence towards the wax moth

374 larvae. Only Proteus sp. (close to P. hauseri) UCMA 3780, H. paralvei 920, and even more $M$.

375 morganii 3A2A and P. heimbachae GR4 strains required the lowest concentrations to kill larvae

376 and can be considered as harbouring efficient virulence factors. Overall, the majority of the

377 strains tested for virulence in Galleria mellonella larvae were safe for this organism when

378 compared with the three control strains known to be safe for use in Humans through oral 379 absorption.

\subsection{Data analysis for safety assessment of GNB associated with traditional French cheeses}

382 A compilation of selected results obtained in the present work (Table S1) provides a global 383 view about main safety characteristics of the tested GNB during simulated GIT transit after oral 384 ingestion of milk products and their potential virulence. In this table, the individual strains were 385 classified from safe to virulent based on the results obtained using the insect model Galleria virulence factors. Among these four strains, M. morganii 3A2A and H. paralvei 920 survived well in aerobic simulated gastric conditions (with milk and bile salts) while the two others

392 survived to a lesser extent. Only one strain, $H$. paralvei 920 , did not grow at $37^{\circ} \mathrm{C}$ under 393 anaerobic conditions. PCA analysis (Figure S2) of the quantitative results given in Table S1, 394 for $\mathrm{pH} 2$ as primary gastric stress, showed some negative correlation $(\mathrm{r}=-0.42)$ between LD50 395 in wax moth larvae and survival in GIM-milk at $\mathrm{pH} 6.5$ with bile salt $(1.5 \mathrm{~g} / \mathrm{L})$. So, the more 396 sensitive the strain to $\mathrm{pH} 2$ (Figure S2A), the higher the value of LD50 (=the less toxic it was); 

at $\mathrm{pH} 4$ (Figure S2B), this negative correlation value was weaker $(\mathrm{r}=-0.29)$ and it could be

398 explained by a lower number of strains sensitive to this less aggressive $\mathrm{pH}$. Furthermore, at 399 $\mathrm{pH} 4$, although adherence to Caco-2 cells and survival were opposed on the F1 axis, no negative 400 correlation appeared $(\mathrm{r}=-0.21)$ between them. Qualitative factors were not specifically 401 associated with any of the quantitative factors studied in Table S1.

402

403

3.6 Safety assessment of GNB strains belonging to genera/species of strains assessed in this 404 study.

To assess the safety status of GNB strains of dairy origin studied here, a bibliographic 406 407 408 409

\section{General discussion and conclusion}


The safety status as well as contribution of most GNB to the cheese process is poorly 423

documented. In previous years, GNB were classically considered as indicators of hygienic problems (Bockelmann et al., 2005; Tornadijo et al., 1993) and responsible for defects in cheese texture and flavor due to the production of extracellular proteolytic and lipolytic enzymes (Amato et al., 2012; Martins et al., 2006). For example, dairy related Pseudomonas spp. strains 427 have been shown to produce volatile compounds such as ethyl esters and alcohols that may 428 negatively affect cheese sensory characteristics (Arslan et al., 2011; Morales et al., 2005). The 429 idea that GNB species can be normal and interesting elements of cheese microbiota is more 430 recent (Larpin-Laborde et al., 2011). In this sense, for example, Proteus sp. (close to P. hauseri) 431 and Psychrobacter sp. have been shown to significantly contribute to flavor production in smear 432 cheeses (Deetae et al., 2007; Irlinger et al., 2012) raising questions about the potential beneficial 433 effects of GNB in general. Recently, it was confirmed that some GNB strains have interesting 434 specific technological properties (Schmitz-Esser et al., 2018).

In this context, to delve deeper into the knowledge about GNB, it was necessary to 436 assess the safety status of these species. The present study was designed to evaluate the potential 437 health risks, if any, associated with the consumption of GNB present in cheeses (and coming 438 from raw milk, milk, or the milking environment), in simulated body conditions. However, risk 439 analysis is complex. You need to know, successively, the danger and its characteristics, the 440 exposure level and to set a safe threshold value, then, and only in that case, risk assessment can 441 be performed. In this study, from the present data and by using a general exposure context, only 442 part of risk analysis (i.e. the qualification of the danger) was done through an in vivo study of 443 pathogenicity in Galleria mellonella larvae and by using in vitro determinations of bacterial 444 growth in the simulated GIT, on Caco-2 cells and in the presence of human serum. The presence 445 of virulent factors was sugested here for some specific GNB strains but their virulence in human 
446 gut also depends on their active dose which is modulated by the effect of different gut barriers,

Data from human consumption can however be considered. In fact, the safety status of cheese in healthy consumers has been recognized for a long time, despite or thanks to microbial strain diversity and microbial interactions in the cheese microbiota that evolves during fermentation and ripening (Imran et al., 2012). Although cheeses have been implicated in $7.8 \%$ of strongly evidenced foodborne outbreaks due to zoonotic agents in the EU (European Food Safety Authority and European Centre for Disease Prevention and Control, 2016; Imran et al., 2012), none of the GNB strains studied here (nor other strains belonging to the same species than those assessed in this study) have been determined to be responsible for any known foodborne outbreaks associated to cheeses. This was also confirmed by our literature analysis described in Table S3. However, two key food risk factors (potential antibiotic resistances and biogenic amine (BA) production, see Table S1) can modulate GNB safety. Assessment of these traits has already been discussed for the 20 selected strains as well as some others (Coton et al., 2012). Particularly of interest is the variable antibiotic resistance profiles observed among certain GNB strains since their genetic material may harbour antibiotic resistance associated genes that may be potentially transferable. Additionnally, the presence of potentially transferable virulence factors in cheese GNB strains must also be underlined.

Up until now, the absence of cheese foodborne outbreaks, might be explained by the positive bioactive impact of the cheese microbial community, as previously demonstrated in a model cheese ecosystem against Listeria monocytogenes (Imran et al., 2013). Additionally, it was also recently shown that Hafnia alvei B16 had an inhibitory effect in a model cheese ecosystem against Escherichia coli O26:H11 (Callon et al., 2016; Delbès-Paus et al., 2013). Multiple dynamic interactions between GIT microbiota, cheese matrix and its initial associated microbiota (detailed in Figure 2) must be taken into account. Among these barriers, 
471 and of special importance is the gut microbiota which was shown to play a crucial role for protection against some pathogenic bacteria (Ubeda et al., 2017). This dense resident microbial community, referred as the commensal microbiota, has a major function of protection against colonization of pathogens and this ability to restrain pathogen growth include competitive metabolic interaction, localization to intestinal niches, and induction of host immune responses (Kumada et al., 2013).

The impact of the dairy matrix on microbial interactions can also lead to changes in functionality such as a means to combat against pathogens as already described (Imran et al., 2012; Imran and Desmasures, 2015). In very recent scientific reports, it has been demonstrated that the dairy matrix also has a significant impact on the survival and immunostimulant ability (treatment of Inflammatory Bowel Diseases) of microbiota in a model gastrointestinal tract and mouse model (Adouard et al., 2016; Foligné et al., 2016; Plé et al., 2015). The role of biliary salts to prevent microbial adherence (Begley et al., 2005) was also recently confirmed (Sanchez et al., 2016). The role of metabolites appearing during digestion must also be detailed.

In silico studies could of help to complete our understanding of these interactions, but it is missing for the GNB studied here. Till now only the genome sequence of several other cheese-related GNB, which include the strain $P$. heimbachae GR4, was determined in a subsequent study (Almeida et al., 2014). It indicated that this strain, studied in this work, is not closely related to the reference strain; an adaptation to the dairy environment could be supposed. For the future, in vivo approaches using wax worm could be further combined with in silico approaches to seek for pathogenicity factors and their potential mobility, in the genome sequence of these strains.

To conclude, presumption of safety of most GNB strains studied here was successfully established, while some could harbour virulence factors. These factors (including some antibiotic resistances) could be considered as a direct or indirect risk when dissemination to 
496 other bacteria of the human gut occured. The role of multiple dynamic interactions between

497 cheese microbiota and GIT barriers including gut microbiota could be key factors explaining

498 safe consumption of the corresponding cheeses. However, the present study, which was partly

499 limited to in vitro studies of selected individual strains, cannot replace in vivo studies involving 500 actual cheese and gut microbiota ecosystem. There is always a gap between microbial behavior 501 in in vitro and in vivo conditions, especially taking into account the complexity of the 502 considered systems (cheese, alimentary bolus, human body). The present approach is a first step 503 for future studies aiming at elucidating the role of each microbial component (GNB or others) 504 within such complex microbial communities.

However, the present study, which was partly limited to in vitro studies of selected 506 individual strains, cannot replace in vivo studies involving actual cheese and gut microbiota 507 ecosystem.

508

\section{Acknowledgements}

This work was funded by the French "Agence Nationale de la Recherche" in the framework of the ANR Gramme project n ${ }^{\circ}$ ANR-07-PNRA-010. The authors would like to thank Valérie Stahl for supplying GNB strains from the Aerial collection, Dr Ulrich Sonnerborn from Ardeypharm 518

\section{REFERENCES}


Adouard, N., Magne, L., Cattenoz, T., Guillemin, H., Foligné, B., Picque, D., Bonnarme, P., 2016. Survival of cheese-ripening microorganisms in a dynamic simulator of the gastrointestinal tract. Food Microbiol. 53, 30-40. https://doi.org/10.1016/j.fm.2015.03.002

Almeida, M., Hébert, A., Abraham, A.-L., Rasmussen, S., Monnet, C., Pons, N., Delbès, C., Loux, V., Batto, J.-M., Leonard, P., Kennedy, S., Ehrlich, S., Pop, M., Montel, M.-C., Irlinger, F., Renault, P., 2014. Construction of a dairy microbial genome catalog opens new perspectives for the metagenomic analysis of dairy fermented products. BMC Genomics 15, 1101. https://doi.org/10.1186/1471-2164-15-1101

Amato, L., Ritschard, J.S., Kurtz, O., Arias-Roth, E., Lacroix, C., Schuppler, M., Meile, L., 2012. Microbial composition of defect smear - A problem evolving during foilprepacked storage of red-smear cheeses. Int. Dairy J. 27, 77-85. https://doi.org/10.1016/j.idairyj.2012.07.012

Aperis, G., Burgwynfuchs, B., Anderson, C., Warner, J., Calderwood, S., Mylonakis, E., 2007. Galleria mellonella as a model host to study infection by the Francisella tularensis live $\begin{array}{lllll}\text { vaccine } & \text { strain. } & \text { Microbes }\end{array}$ https://doi.org/10.1016/j.micinf.2007.02.016

Arslan, S., Eyi, A., Özdemir, F., 2011. Spoilage potentials and antimicrobial resistance of Pseudomonas spp. isolated from cheeses. J. Dairy Sci. 94, 5851-5856. https://doi.org/10.3168/jds.2011-4676

Begley, M., Gahan, C.G.M., Hill, C., 2005. The interaction between bacteria and bile. FEMS Microbiol. Rev. 29, 625-651. https://doi.org/10.1016/j.femsre.2004.09.003

Bockelmann, W., Willems, K.P., Neve, H., Heller, K.H., 2005. Cultures for the ripening of smear cheeses. Int. Dairy J. 15, 719-732. https://doi.org/10.1016/j.idairyj.2004.08.022

Callon, C., Arliguie, C., Montel, M.C., 2016. Control of Shigatoxin-producing Escherichia coli in cheese by dairy bacterial strains. Food Microbiol. 53, 63-70. https://doi.org/10.1016/j.fm.2015.08.009

Champion, O.L., Cooper, I.A.M., James, S.L., Ford, D., Karlyshev, A., Wren, B.W., Duffield, M., Oyston, P.C.F., Titball, R.W., 2009. Galleria mellonella as an alternative infection model for Yersinia pseudotuberculosis. Microbiology 155, 1516-1522. https://doi.org/10.1099/mic.0.026823-0

Chateau, N., Deschamps, A.M., Sassi, A.H., 1994. Heterogeneity of bile salts resistance in the Lactobacillus isolates of a probiotic consortium. Lett. Appl. Microbiol. 18, 42-44. https://doi.org/10.1111/j.1472-765X.1994.tb00796.x

Chaves-Lopez, C., De Angelis, M., Martuscelli, M., Serio, A., Paparella, A., Suzzi, G., 2006. Characterization of the Enterobacteriaceae isolated from an artisanal Italian ewe's cheese (Pecorino Abruzzese). J. Appl. Microbiol. 101, 353-360. https://doi.org/10.1111/j.1365-2672.2006.02941.x

Clavel, T., Carlin, F., Dargaignaratz, C., Lairon, D., Nguyen-The, C., Schmitt, P., 2007. Effects of porcine bile on survival of Bacillus cereus vegetative cells and Haemolysin BL enterotoxin production in reconstituted human small intestine media: B. cereus and porcine bile. J. Appl. Microbiol. 103, 1568-1575. https://doi.org/10.1111/j.13652672.2007.03410.x

Clavel, T., Carlin, F., Lairon, D., Nguyen-The, C., Schmitt, P., 2004. Survival of Bacillus cereus spores and vegetative cells in acid media simulating human stomach. J. Appl. Microbiol. 97, 214-219. https://doi.org/10.1111/j.1365-2672.2004.02292.x

Coton, M., Delbés-Paus, C., Irlinger, F., Desmasures, N., Le Fleche, A., Stahl, V., Montel, M.C., Coton, E., 2012. Diversity and assessment of potential risk factors of Gram-negative isolates associated with French cheeses. Food Microbiol. 29, 88-98. https://doi.org/10.1016/j.fm.2011.08.020 
Deetae, P., Bonnarme, P., Spinnler, H.E., Helinck, S., 2007. Production of volatile aroma compounds by bacterial strains isolated from different surface-ripened French cheeses. Appl. Microbiol. Biotechnol. 76, 1161-1171. https://doi.org/10.1007/s00253-0071095-5

Delbes, C., Ali-Mandjee, L., Montel, M.-C., 2007. Monitoring Bacterial Communities in Raw Milk and Cheese by Culture-Dependent and -Independent 16S rRNA Gene-Based Analyses. Appl. Environ. Microbiol. 73, 1882-1891. https://doi.org/10.1128/AEM.01716-06

Delbès-Paus, C., Miszczycha, S., Ganet, S., Helinck, S., Veisseire, P., Pochet, S., Thévenot, D., Montel, M.-C., 2013. Behavior of Escherichia coli O26:H11 in the presence of Hafnia alvei in a model cheese ecosystem. Int. J. Food Microbiol. 160, 212-218. https://doi.org/10.1016/j.ijfoodmicro.2012.10.019

Delbès-Paus, C., Pochet, S., Helinck, S., Veisseire, P., Bord, C., Lebecque, A., Coton, M., Desmasures, N., Coton, E., Irlinger, F., Montel, M.-C., 2012. Impact of Gram-negative bacteria in interaction with a complex microbial consortium on biogenic amine content and sensory characteristics of an uncooked pressed cheese. Food Microbiol. 30, 74-82. https://doi.org/10.1016/j.fm.2011.12.008

Desbois, A.P., Coote, P.J., 2012. Utility of Greater Wax Moth Larva (Galleria mellonella) for Evaluating the Toxicity and Efficacy of New Antimicrobial Agents, in: Advances in Applied Microbiology. Elsevier, pp. 25-53. https://doi.org/10.1016/B978-0-12394805-2.00002-6

Desmasures, N., Opportune, W., Guéguen, M., 1997. Lactococcus spp., yeasts and Pseudomonas spp. on teats and udders of milking cows as potential sources of milk contamination. Int. Dairy J. 7, 643-646. https://doi.org/10.1016/S0958-6946(97)000423

dos Santos, P.A., Pereira, A.C.M., Ferreira, A.F., de Mattos Alves, M.A., Rosa, A.C.P., FreitasAlmeida, A.C., 2015. Adhesion, invasion, intracellular survival and cytotoxic activity of strains of Aeromonas spp. in HEp-2, Caco-2 and T-84 cell lines. Antonie Van Leeuwenhoek 107, 1225-1236. https://doi.org/10.1007/s10482-015-0416-4

Dugat-Bony, E., Garnier, L., Denonfoux, J., Ferreira, S., Sarthou, A.S., Bonnarme, P., Irlinger, F., 2016. Highlighting the microbial diversity of 12 French cheese varieties. Int. J. Food Microbiol. 238, 265-273. https://doi.org/10.1016/j.ijfoodmicro.2016.09.026

EFSA Panel on Biological Hazards (BIOHAZ), 2014. Statement on the update of the list of QPS-recommended biological agents intentionally added to food or feed as notified to EFSA 1: Suitability of taxonomic units notified to EFSA until October 2014. EFSA J. 12. https://doi.org/10.2903/j.efsa.2014.3938

European Food Safety Authority, European Centre for Disease Prevention and Control, 2016. The European Union summary report on trends and sources of zoonoses, zoonotic agents and food-borne outbreaks in 2015. EFSA J. 14. https://doi.org/10.2903/j.efsa.2016.4634

Fogh, J., Fogh, J.M., Orfeo, T., 1977. One hundred and twenty-seven cultured human tumor cell lines producing tumors in nude mice. J. Natl. Cancer Inst. 59, 221-226.

Foligné, B., Parayre, S., Cheddani, R., Famelart, M.-H., Madec, M.-N., Plé, C., Breton, J., Dewulf, J., Jan, G., Deutsch, S.-M., 2016. Immunomodulation properties of multispecies fermented milks. Food Microbiol. 53, 60-69. https://doi.org/10.1016/j.fm.2015.04.002

Frétin, M., Martin, B., Rifa, E., Isabelle, V.-M., Pomiès, D., Ferlay, A., Montel, M.-C., Delbès, C., 2018. Bacterial community assembly from cow teat skin to ripened cheeses is influenced by grazing systems. Sci. Rep. 8, 200. https://doi.org/10.1038/s41598-01718447-y 
Gänzle, M.G., Hertel, C., van der Vossen, J.M., Hammes, W.P., 1999. Effect of bacteriocinproducing lactobacilli on the survival of Escherichia coli and Listeria in a dynamic model of the stomach and the small intestine. Int. J. Food Microbiol. 48, 21-35.

Gopal, P.K., Prasad, J., Smart, J., Gill, H.S., 2001. In vitro adherence properties of Lactobacillus rhamnosus DR20 and Bifidobacterium lactis DR10 strains and their antagonistic activity against an enterotoxigenic Escherichia coli. Int. J. Food Microbiol. 67, 207-216.

Gori, K., Ryssel, M., Arneborg, N., Jespersen, L., 2013. Isolation and Identification of the Microbiota of Danish Farmhouse and Industrially Produced Surface-Ripened Cheeses. Microb. Ecol. 65, 602-615. https://doi.org/10.1007/s00248-012-0138-3

Greene, J.D., Klaenhammer, T.R., 1994. Factors involved in adherence of lactobacilli to human Caco-2 cells. Appl. Environ. Microbiol. 60, 4487-4494.

Hyronimus, B., Le Marrec, C., Sassi, A.H., Deschamps, A., 2000. Acid and bile tolerance of spore-forming lactic acid bacteria. Int. J. Food Microbiol. 61, 193-197.

Imran, M., Bré, J.-M., Guéguen, M., Vernoux, J.-P., Desmasures, N., 2013. Reduced growth of Listeria monocytogenes in two model cheese microcosms is not associated with individual microbial strains. Food Microbiol. 33, 30-39. https://doi.org/10.1016/j.fm.2012.08.008

Imran, M., Desmasures, N., 2015. Safety and Quality Aspects of Smear Ripened Cheeses, in: Bora, N., Dodd, C., Desmasures, N. (Eds.), Diversity, Dynamics and Functional Role of Actinomycetes on European Smear Ripened Cheeses. Springer International Publishing, Cham, pp. 199-215. https://doi.org/10.1007/978-3-319-10464-5_9

Imran, M., Desmasures, N., Vernoux, J.-P., 2012. Complex Microbial Communities as Part of Fermented Food Ecosystems and Beneficial Properties, in: Mehta, B., Kamal-Eldin, A., Iwanski, R. (Eds.), Fermentation. CRC Press. https://doi.org/10.1201/b11876-3

Irlinger, F., In Yung, S.A.Y., Sarthou, A.-S., Delbès-Paus, C., Montel, M.-C., Coton, E., Coton, M., Helinck, S., 2012. Ecological and aromatic impact of two Gram-negative bacteria (Psychrobacter celer and Hafnia alvei) inoculated as part of the whole microbial community of an experimental smear soft cheese. Int. J. Food Microbiol. 153, 332-338. https://doi.org/10.1016/j.ijfoodmicro.2011.11.022

Irlinger, F., Mounier, J., 2009. Microbial interactions in cheese: implications for cheese quality and safety. Curr. Opin. Biotechnol. 20, 142-148. https://doi.org/10.1016/j.copbio.2009.02.016

Jander, G., Rahme, L.G., Ausubel, F.M., 2000. Positive correlation between virulence of Pseudomonas aeruginosa mutants in mice and insects. J. Bacteriol. 182, 3843-3845.

Jankowski, S., Rowiński, S., Cisowska, A., Gamian, A., 1996. The sensitivity of Hafnia alvei strains to the bactericidal effect of serum. FEMS Immunol. Med. Microbiol. 13, 59-64.

Kable, M.E., Srisengfa, Y., Laird, M., Zaragoza, J., McLeod, J., Heidenreich, J., Marco, M.L., 2016. The Core and Seasonal Microbiota of Raw Bovine Milk in Tanker Trucks and the Impact of Transfer to a Milk Processing Facility. mBio 7, e00836-16. https://doi.org/10.1128/mBio.00836-16

Kavanagh, K., Reeves, E.P., 2004. Exploiting the potential of insects for in vivo pathogenicity testing of microbial pathogens. FEMS Microbiol. Rev. 28, 101-112. https://doi.org/10.1016/j.femsre.2003.09.002

Kamada, N., Chen, G.Y., Inohara, N., Núñez, G., 2013. Control of Pathogens and Pathobionts by the Gut Microbiota. Nat Immunol. 2013 July ; 14(7): 685-690. doi:10.1038/ni.2608.

King, L.B., Swiatlo, E., Swiatlo, A., McDaniel, L.S., 2009. Serum resistance and biofilm formation in clinical isolates of Acinetobacter baumannii. FEMS Immunol. Med. Microbiol. 55, 414-421. https://doi.org/10.1111/j.1574-695X.2009.00538.x 
Larpin-Laborde, S., Imran, M., Bonaïti, C., Bora, N., Gelsomino, R., Goerges, S., Irlinger, F., Goodfellow, M., Ward, A.C., Vancanneyt, M., Swings, J., Scherer, S., Guéguen, M., Desmasures, N., 2011. Surface microbial consortia from Livarot, a French smearripened cheese. Can. J. Microbiol. 57, 651-660. https://doi.org/10.1139/w11-050

673

674

675

676

677

678

679

680

681

682

683

684

685

686

687

688

689

690

691

692

693

694

695

696

697

698

699

700

701

702

703

704

705

706

707

708

709

710

711

712

713

714

715

716

717

718

719

720

Lorke, D., 1983. A new approach to practical acute toxicity testing. Arch. Toxicol. 54, 275287.

Maoz, A., Mayr, R., Scherer, S., 2003. Temporal Stability and Biodiversity of Two Complex Antilisterial Cheese-Ripening Microbial Consortia. Appl. Environ. Microbiol. 69, 4012-4018. https://doi.org/10.1128/AEM.69.7.4012-4018.2003

Martín, J.F., Coton, M., 2017. Blue Cheese, in: Fermented Foods in Health and Disease Prevention. Elsevier, pp. 275-303. https://doi.org/10.1016/B978-0-12-8023099.00012-1

Martins, M.L., Pinto, C.L.O., Rocha, R.B., de Araújo, E.F., Vanetti, M.C.D., 2006. Genetic diversity of Gram-negative, proteolytic, psychrotrophic bacteria isolated from refrigerated raw milk. Int. J. Food Microbiol. 111, 144-148. https://doi.org/10.1016/j.ijfoodmicro.2006.06.020

Montel, M.-C., Buchin, S., Mallet, A., Delbes-Paus, C., Vuitton, D.A., Desmasures, N., Berthier, F., 2014. Traditional cheeses: Rich and diverse microbiota with associated benefits. Int. J. Food Microbiol. 177, 136-154. https://doi.org/10.1016/j.ijfoodmicro.2014.02.019

Morales, P., Fernández-García, E., Nuñez, M., 2005. Production of volatile compounds in cheese by Pseudomonas fragi strains of dairy origin. J. Food Prot. 68, 1399-1407.

Morgan, B.P., Daha, M., Meri, S., Nicholson-Weller, A., 2000. Into the third century of complement research. Immunol. Today 21, 603-605.

Morton, D.B., Dunphy, G.B., Chadwick, J.S., 1987. Reactions of hemocytes of immune and non-immune Galleria mellonella larvae to Proteus mirabilis. Dev. Comp. Immunol. 11, $47-55$.

Mounier, J., Coton, M., Irlinger, F., Landaud, S., Bonnarme, P., 2017. Smear-Ripened Cheeses, in: Cheese. Elsevier, pp. 955-996. https://doi.org/10.1016/B978-0-12-417012-4.000387

Mounier, J., Gelsomino, R., Goerges, S., Vancanneyt, M., Vandemeulebroecke, K., Hoste, B., Scherer, S., Swings, J., Fitzgerald, G.F., Cogan, T.M., 2005. Surface Microflora of Four Smear-Ripened Cheeses. Appl. Environ. Microbiol. 71, 6489-6500. https://doi.org/10.1128/AEM.71.11.6489-6500.2005

Mounier, J., Goerges, S., Gelsomino, R., Vancanneyt, M., Vandemeulebroecke, K., Hoste, B., Brennan, N.M., Scherer, S., Swings, J., Fitzgerald, G.F., Cogan, T.M., 2006. Sources of the adventitious microflora of a smear-ripened cheese. J. Appl. Microbiol. 101, 668681. https://doi.org/10.1111/j.1365-2672.2006.02922.x

Mounier, J., Monnet, C., Jacques, N., Antoinette, A., Irlinger, F., 2009. Assessment of the microbial diversity at the surface of Livarot cheese using culture-dependent and independent approaches. Int. J. Food Microbiol. 133, 31-37. https://doi.org/10.1016/j.ijfoodmicro.2009.04.020

Nicoletti, M., Iacobino, A., Prosseda, G., Fiscarelli, E., Zarrilli, R., De Carolis, E., Petrucca, A., Nencioni, L., Colonna, B., Casalino, M., 2011. Stenotrophomonas maltophilia strains from cystic fibrosis patients: Genomic variability and molecular characterization of some virulence determinants. Int. J. Med. Microbiol. 301, 34-43. https://doi.org/10.1016/j.ijmm.2010.07.003

Pavlov, D., de Wet, C.M.., Grabow, W.O.., Ehlers, M.., 2004. Potentially pathogenic features of heterotrophic plate count bacteria isolated from treated and untreated drinking water. Int. J. Food Microbiol. 92, 275-287. https://doi.org/10.1016/j.ijfoodmicro.2003.08.018 
Pinto, M., Robine-Leon, S., Appay, M., Kedinger, M., Triadou, N., Dussaulx, E., Lacroix, B., Simon-Assmann, P., Haffen, K., Fogh, J., Zweibaum, A., 1983. Enterocyte-like differentiation and polarization of the Human colon carcinoa cell line Caco-2 in culture 47, 323-330.

Plé, C., Adouard, N., Breton, J., Dewulf, J., Pot, B., Bonnarme, P., Foligné, B., 2015. Designing specific cheese-ripening ecosystems to shape the immune effects of dairy products? J. Funct. Foods 12, 219-229. https://doi.org/10.1016/j.jff.2014.11.021

Pogačar, M.Š., Klančnik, A., Bucar, F., Langerholc, T., Možina, S.S., 2015. Alpinia katsumadai Extracts Inhibit Adhesion and Invasion of Campylobacter jejuni in Animal and Human Foetal Small Intestine Cell Lines: Inhibition of Campylobacter Adhesion in Cell Lines. Phytother. Res. 29, 1585-1589. https://doi.org/10.1002/ptr.5396

Quin, L.R., Onwubiko, C., Carmicle, S., McDaniel, L.S., 2006. Interaction of clinical isolates of Streptococcus pneumoniae with human complement factor H. FEMS Microbiol. Lett. 264, 98-103. https://doi.org/10.1111/j.1574-6968.2006.00439.x

Ramarao, N., Nielsen-Leroux, C., Lereclus, D., 2012. The Insect Galleria mellonella as a Powerful Infection Model to Investigate Bacterial Pathogenesis. J. Vis. Exp. https://doi.org/10.3791/4392

Salamitou, S., Ramisse, F., Brehélin, M., Bourguet, D., Gilois, N., Gominet, M., Hernandez, E., Lereclus, D., 2000. The plcR regulon is involved in the opportunistic properties of Bacillus thuringiensis and Bacillus cereus in mice and insects. Microbiol. Read. Engl. 146 ( Pt 11), 2825-2832. https://doi.org/10.1099/00221287-146-11-2825

Sanchez, L.M., Cheng, A.T., Warner, C.J.A., Townsley, L., Peach, K.C., Navarro, G., Shikuma, N.J., Bray, W.M., Riener, R.M., Yildiz, F.H., Linington, R.G., 2016. Biofilm Formation and Detachment in Gram-Negative Pathogens Is Modulated by Select Bile Acids. PLOS ONE 11, e0149603. https://doi.org/10.1371/journal.pone.0149603

Schmitz-Esser, S., Dzieciol, M., Nischler, E., Schornsteiner, E., Bereuter, O., Mann, E., Wagner, M., 2018. Abundance and potential contribution of Gram-negative cheese rind bacteria from Austrian artisanal hard cheeses. Int. J. Food Microbiol. 266, 95-103. https://doi.org/10.1016/j.ijfoodmicro.2017.11.013

Shimakawa, Y., Matsubara, S., Yuki, N., Ikeda, M., Ishikawa, F., 2003. Evaluation of Bifidobacterium breve strain Yakult-fermented soymilk as a probiotic food. Int. J. Food Microbiol. 81, 131-136.

Tareb, R., Bernardeau, M., Gueguen, M., Vernoux, J.-P., 2013. In vitro characterization of aggregation and adhesion properties of viable and heat-killed forms of two probiotic Lactobacillus strains and interaction with foodborne zoonotic bacteria, especially Campylobacter jejuni. J. Med. Microbiol. 62, 637-649. https://doi.org/10.1099/jmm.0.049965-0

Tornadijo, E., Fresno, J.M., Carballo, J., Martín-Sarmiento, R., 1993. Study of Enterobacteriaceae throughout the manufacturing and ripening of hard goats' cheese. J. Appl. Bacteriol. 75, 240-246. https://doi.org/10.1111/j.1365-2672.1993.tb02772.x

Vernozy-Rozand, C., Feng, P., Montet, M.-P., Ray-Gueniot, S., Villard, L., Bavai, C., Meyrand, A., Mazuy, C., Atrache, V., 2000. Detection of Escherichia coli O157:H7 in heifers' faecal samples using an automated immunoconcentration system. Lett. Appl. Microbiol. 30, 217-222. https://doi.org/10.1046/j.1472-765x.2000.00702.x

Walters, J.B., Ratcliffe, N.A., 1983. Studies on the in vivo cellular reactions of insects: Fate of pathogenic and non-pathogenic bacteria in Galleria mellonella nodules. J. Insect Physiol. 29, 417-424. https://doi.org/10.1016/0022-1910(83)90069-0

Wand, M.E., McCowen, J.W.I., Nugent, P.G., Sutton, J.M., 2013. Complex interactions of Klebsiella pneumoniae with the host immune system in a Galleria mellonella infection model. J. Med. Microbiol. 62, 1790-1798. https://doi.org/10.1099/jmm.0.063032-0 
Wassenaar, T.M., 2016. Insights from 100 years of research with probiotic E. coli. Eur. J. Microbiol. Immunol. 6, 147-161. https://doi.org/10.1556/1886.2016.00029

Wolfe, B.E., Button, J.E., Santarelli, M., Dutton, R.J., 2014. Cheese rind communities provide tractable systems for in situ and in vitro studies of microbial diversity. Cell 158, 422433. https://doi.org/10.1016/j.cell.2014.05.041

Ubeda, C., Djukovic, A., Isaac., S., 2017. Roles of the intestinal microbiota in pathogen protection. Clinical \& Translational Immunology (2017) 6, e128; doi:10.1038/cti.2017.2

Zhao, X., Zhong, J., Wei, C., Lin, C.-W., Ding T., 2017. Current Perspectives on Viable but Non-culturable State in Foodborne Pathogens. Front. Microbiol. 8:580. doi:10.3389/fmicb.2017.00580 
Table 1. Identification of representative Gram-negative bacterial strains of dairy origin used in this study. Growth in anaerobic or aerobic conditions at $37^{\circ} \mathrm{C}$ was assessed in the 788 present study.

\begin{tabular}{|c|c|c|c|}
\hline Species & Code & Dairy source & $\begin{array}{c}\text { Growth in } \\
\text { anaerobic/aerobic } \\
\text { condition at } 37^{\circ} \mathrm{C}^{*}\end{array}$ \\
\hline Acinetobacter close to $A$. genospecies 3 & PCAi E6.10 & Milk from Salers cow & $-/+$ \\
\hline Alcaligenes faecalis & 904 & Smear-ripened cheese & $-/-$ \\
\hline Chryseobacterium close to $C$. bovis & Pi18 & Uncooked pressed cheese & $+/+$ \\
\hline Citrobacter freundii & UCMA 4217 & Smear-ripened cheese & $+/+$ \\
\hline Hafnia alvei (biogroup 1) & B16 & Smear-ripened cheese & $+/+$ \\
\hline Hafnia paralvei & 920 & Smear-ripened cheese & $-/+$ \\
\hline Halomonas venusta/ alkaliphila/ hydrothermalis & $4 \mathrm{C} 1 \mathrm{~A}$ & Smear-ripened cheese & $+/+$ \\
\hline Halomonas sp. nov. & B39 & Smear-ripened cheese & $-/+$ \\
\hline Klebsiella oxytoca & 927 & Smear-ripened cheese & $+/+$ \\
\hline Morganella morganii & $3 \mathrm{~A} 2 \mathrm{~A}$ & Smear-ripened cheese & $+/+$ \\
\hline Pantoea agglomerans & PCA Q6.3 & Milk & $+/+$ \\
\hline Proteus sp. close to $P$. hauseri & UCMA 3779 & Smear-ripened cheese & $-/+$ \\
\hline Proteus sp. close to P. hauseri & UCMA 3780 & Smear-ripened cheese & $+/+$ \\
\hline Providencia heimbachae & GR4 & Smear-ripened cheese & $+/+$ \\
\hline Pseudomonas group putida & VRBG37.3 & Milk & $+/+$ \\
\hline Pseudomonas group putida & CV30.6 & Milk & $-/+$ \\
\hline Pseudomonas stutzeri & UCMA 3883 & Smear-ripened cheese & $-/+$ \\
\hline Psychrobacter celer & 91 & Mould-ripened soft cheese & $-/+$ \\
\hline Sphingobacterium sp. close to S. faecium & PCAi F2.5 & Milk & $+/+$ \\
\hline Stenotrophomonas maltophilia/rhizophila & PCAi D6.5 & Milk & $+/+$ \\
\hline
\end{tabular}

*all strains grew at $25^{\circ} \mathrm{C}$ in aerobic conditions 
Table 2. Survival of Gram-negative bacteria of dairy origin (inoculated at $\mathbf{N}_{\mathbf{0}}=\mathbf{1 0}^{6} \mathbf{c f u} / \mathbf{m l}$ ) 793 in in vitro simulated conditions related to gastric media (GM) and gastrointestinal (GIM) 794 stress. Results are presented as the $\log (\mathrm{N} / \mathrm{N} 0)$ where $\mathrm{N}$ is the number of CFU/ml after $3 \mathrm{~h}$ 795 gastric stress (GM-3) followed by $28 \mathrm{~h}$ gastrointestinal stress simulation, with or without bile 796 797 salts (GIM-28), corresponding to a total of $31 \mathrm{~h}$ of (GM+GIM) stress.

\begin{tabular}{|c|c|c|c|c|c|c|c|c|c|}
\hline \multirow[b]{4}{*}{ Gram negative bacterial strains } & \multirow{4}{*}{ Bile $\mathbf{g} / \mathbf{L}$} & \multicolumn{4}{|c|}{$\mathrm{pH} 4.0$ at $\mathrm{T}_{0}$} & \multicolumn{4}{|c|}{$\mathrm{pH} 2.0$ at $\mathrm{T}_{0}$} \\
\hline & & \multicolumn{2}{|c|}{ GM-JB } & \multicolumn{2}{|c|}{ GM-milk } & \multicolumn{2}{|c|}{ GM-JB } & \multicolumn{2}{|c|}{ GM-milk } \\
\hline & & \multicolumn{8}{|c|}{ Time (h) of exposure with pH change to 6.5 at $T+3 h$} \\
\hline & & 3 & 31 & 3 & 31 & 3 & 31 & 3 & 31 \\
\hline \multirow{2}{*}{$\begin{array}{l}\text { Acinetobacter (close to } A \text {. genospecies } 3 \text { ) } \\
\text { PCAi E6.10 }\end{array}$} & $\mathbf{0}$ & 0.49 & 2.72 & 0.01 & 3.23 & 0.44 & 2.66 & -5.74 & -5.74 \\
\hline & 1.5 & & 3.01 & & 2.62 & & 0.73 & & -2.84 \\
\hline \multirow{2}{*}{ Alcaligenes faecalis 904} & $\mathbf{0}$ & -5.20 & -5.20 & -4.81 & -4.81 & -3.30 & -3.30 & -5.20 & -5.20 \\
\hline & 1.5 & & -5.20 & & -4.81 & & -3.30 & & -5.20 \\
\hline \multirow{2}{*}{ Chryseobacterium (close to C. bovis) Pi18 } & 0 & 0.22 & 1.15 & 0.06 & -1.48 & -2.24 & -5.84 & -0.17 & -3.55 \\
\hline & 1.5 & & 2.57 & & -1.47 & & -5.84 & & -5.85 \\
\hline \multirow{2}{*}{ Citrobacter freundii UCMA 4217} & $\mathbf{0}$ & -0.11 & 4.04 & 0.85 & 3.25 & -5.55 & -2.94 & -5.85 & -2.85 \\
\hline & 1.5 & & 3.91 & & 2.95 & & -2.77 & & -2.64 \\
\hline \multirow{2}{*}{ Hafnia alvei (biogroup 1) B16 } & 0 & 0.40 & 3.43 & 0.53 & 3.16 & -5.90 & -5.90 & -6.06 & -2.86 \\
\hline & 1.5 & & 3.53 & & 3.08 & & -5.90 & & -2.99 \\
\hline \multirow{2}{*}{ Hafnia paralvei 920} & $\mathbf{0}$ & -0.48 & 3.26 & 0.15 & 3.12 & -0.32 & -5.99 & -0.11 & 2.56 \\
\hline & 1.5 & & 3.14 & & 3.46 & & -5.99 & & 2.95 \\
\hline \multirow{2}{*}{$\begin{array}{l}\text { Halomonas } \\
\text { venusta/alkaliphila/hydrothermas } 4 \mathrm{C} 1 \mathrm{~A}\end{array}$} & $\mathbf{0}$ & 0.65 & 3.10 & -1.28 & 2.03 & 0.92 & 3.55 & -0.39 & -5.82 \\
\hline & 1.5 & & 3.23 & & 1.73 & & 3.62 & & -5.82 \\
\hline \multirow{2}{*}{ Halomonas sp. nov. B39 } & $\mathbf{0}$ & -0.10 & 3.91 & 0.22 & 3.64 & -5.66 & -1.03 & -0.17 & 3.87 \\
\hline & 1.5 & & 3.89 & & 3.40 & & -0.88 & & 3.84 \\
\hline \multirow{2}{*}{ Klebsiella oxytoca 927} & $\mathbf{0}$ & -0.62 & 3.86 & -0.26 & 3.59 & -3.60 & -3.60 & -5.55 & 0.95 \\
\hline & 1.5 & & 3.64 & & 3.93 & & -3.60 & & 1.24 \\
\hline \multirow{2}{*}{ Morganella morganii $3 \mathrm{~A} 2 \mathrm{~A}$} & $\mathbf{0}$ & -0.29 & 2.75 & -0.34 & -0.13 & -0.93 & -6.24 & -0.06 & -6.12 \\
\hline & 1.5 & & 2.85 & & -0.07 & & -3.64 & & 0.20 \\
\hline \multirow{2}{*}{ Pantoea agglomerans PCA Q6.3 } & $\mathbf{0}$ & 0.40 & 3.37 & 0.23 & 3.17 & 0.51 & 3.50 & -5.41 & -0.94 \\
\hline & 1.5 & & 3.42 & & 3.19 & & 3.42 & & -0.93 \\
\hline \multirow{2}{*}{ Proteus sp. (close P. hauseri) UCMA 3779} & $\mathbf{0}$ & -0.24 & 2.91 & 0.21 & 2.86 & -6.00 & -6.00 & -6.70 & -6.70 \\
\hline & 1.5 & & 3.47 & & 2.15 & & -6.00 & & -6.70 \\
\hline \multirow{2}{*}{ Proteus sp. (close P. hauseri) UCMA 3780} & $\mathbf{0}$ & -0.05 & 3.41 & -0.54 & -0.74 & -5.83 & -5.83 & -1.39 & 2.00 \\
\hline & 1.5 & & 3.90 & & 2.90 & & -5.83 & & 2.17 \\
\hline & $\mathbf{0}$ & 0.19 & 2.87 & -0.17 & 0.86 & 0.58 & 3.09 & -0.46 & -2.97 \\
\hline Providencia heimbachae GR4 & 1.5 & & 2.76 & & 0.98 & & 2.19 & & -2.85 \\
\hline & $\mathbf{0}$ & -1.04 & -5.45 & -1.99 & -5.59 & -5.61 & -3.31 & -4.20 & -4.20 \\
\hline Pseudomonas group putida VRBG37.3 & 1.5 & & 2.56 & & -3.29 & & -2.83 & & -4.20 \\
\hline & $\mathbf{0}$ & 0.38 & 3.44 & -0.13 & 2.61 & -6.38 & -6.38 & -0.32 & -6.31 \\
\hline Pseudomonas group putida CV30.6 & 1.5 & & 3.37 & & 3.01 & & -6.38 & & -6.31 \\
\hline & $\mathbf{0}$ & 0.68 & 3.97 & 0.16 & 3.30 & -5.92 & -5.92 & -5.75 & -5.75 \\
\hline Pseudomonas stutzeri UCMA 3883 & 1.5 & & 3.34 & & 4.45 & & -5.92 & & -5.75 \\
\hline & $\mathbf{0}$ & 0.47 & 3.26 & -0.16 & 3.05 & -6.05 & -6.05 & -5.68 & -5.68 \\
\hline Psychrobacter celer 91 & 1.5 & & 3.45 & & 3.58 & & -6.05 & & -5.68 \\
\hline Sphingobacterium sp. (close to S. faecium) & $\mathbf{0}$ & 0.20 & 3.56 & -1.32 & 2.71 & -0.36 & 3.90 & -5.30 & -2.15 \\
\hline PCAi F2.5 & 1.5 & & 3.63 & & 2.73 & & 3.28 & & -1.74 \\
\hline Stenotrophomonas maltophilia/rhizophila & $\mathbf{0}$ & -0.23 & 4.29 & -0.52 & 0.26 & -4.15 & -4.15 & -5.14 & -2.84 \\
\hline PCAi D6.5 & 1.5 & & 3.93 & & -2.79 & & -4.15 & & -5.14 \\
\hline
\end{tabular}


800 Table 3. Adhesion to Caco-2 cells, sensitivity to human serum and increasing in vivo 801 pathogenicity on wax moth worm of the tested Gram-negative bacteria of dairy origin.

802

803

\begin{tabular}{|c|c|c|c|}
\hline Identification & $\begin{array}{l}\text { No. bacterial cell } \\
\text { adhering } \\
\text { to } 100 \mathrm{Caco-2*} \\
\end{array}$ & $\begin{array}{c}\text { Sensitivity } \\
\text { to human } \\
\text { serum }\end{array}$ & $\begin{array}{l}50 \% \text { lethal dose at } 72 \mathrm{~h} \\
\text { (CFU/g of larva*) }\end{array}$ \\
\hline \multicolumn{4}{|l|}{ Control strains for safety } \\
\hline Lactobacillus rhamnosus $\mathrm{GG}(\mathrm{Gram}+)$ & 200 & nd & $7.0010^{8}$ \\
\hline Escherichia coli Nissle 1917 & 23 & nd & $1.7010^{7}$ \\
\hline Escherichia coli K12 ATCC 10798 & 65 & nd & $3.1610^{7}$ \\
\hline \multicolumn{4}{|l|}{ Strain with intimin } \\
\hline Escherichia coli $\mathrm{O} 157: \mathrm{H} 7 \mathrm{C} 267\left(e^{+} e^{+}\right.$, stx-) & 35 & nd & $1.4610^{6}$ \\
\hline \multicolumn{4}{|l|}{ Dairy strains } \\
\hline $\begin{array}{l}\text { Chryseobacterium sp (close to C. bovis) } \\
\text { Pi } 18\end{array}$ & 73 & $\mathrm{R}$ & $3.7110^{8}$ \\
\hline Psychrobacter celer 91 & 145 & S & $1.4110^{8}$ \\
\hline Alcaligenes faecalis 904 & 200 & $\mathrm{R}$ & $9.8310^{7}$ \\
\hline $\begin{array}{l}\text { Proteus sp. (close to P. hauseri) UCMA } \\
3779\end{array}$ & 58 & $\mathrm{R}$ & $9.7810^{7}$ \\
\hline $\begin{array}{l}\text { Acinetobacter sp. (close to A. genospecies } \\
\text { 3) PCAi E6.10 }\end{array}$ & 33 & $\mathrm{R}$ & $8.8210^{7}$ \\
\hline $\begin{array}{l}\text { Halomonas venusta/alkaliphila/ } \\
\text { hydrothermalis } 4 \mathrm{C} 1 \mathrm{~A}\end{array}$ & 363 & $\mathrm{~S}$ & $6.0610^{7}$ \\
\hline Pantoea agglomerans PCA Q6.3 & 63 & $\mathrm{R}$ & $5.9110^{7}$ \\
\hline Halomonas sp. nov. B39 & 30 & $\mathrm{~S}$ & $2.5410^{7}$ \\
\hline Citrobacter freundii UCMA 4217 & 100 & $\mathrm{R}$ & $2.1810^{7}$ \\
\hline Pseudomonas group putida VRBG 37.3 & 141 & $\mathrm{~S}$ & $1.9110^{7}$ \\
\hline $\begin{array}{l}\text { Stenotrophomonas maltophilia/rhizophila } \\
\text { PCAi D6.5 }\end{array}$ & 70 & $\mathrm{R}$ & $1.3310^{7}$ \\
\hline Pseudomonas group putida CV30.6 & 5 & $\mathrm{R}$ & $1.2510^{7}$ \\
\hline Hafnia alvei biogroup 1 B16 & 43 & $\mathrm{R}$ & $9.4810^{6}$ \\
\hline Pseudomonas stutzeri UCMA 3883 & 114 & $\mathrm{R}$ & $6.5710^{6}$ \\
\hline $\begin{array}{l}\text { Sphingobacterium sp. (close to S. faecium) } \\
\text { PCAi F2.5 }\end{array}$ & 45 & $\mathrm{~S}$ & $6.5710^{6}$ \\
\hline Klebsiella oxytoca 927 & 138 & $\mathrm{R}$ & $6.1310^{6}$ \\
\hline Hafnia paralvei 920 & 36 & $\mathrm{R}$ & $2.8010^{5}$ \\
\hline $\begin{array}{l}\text { Proteus sp. (close to P. hauseri) UCMA } \\
3780\end{array}$ & 152 & $\mathrm{R}$ & $9.6310^{4}$ \\
\hline Providencia heimbachae GR4 & 49 & $\mathrm{R}$ & $<1.610^{4}$ \\
\hline Morganella morganii 3A2A & 54 & $\mathrm{R}$ & $<1.1610^{4}$ \\
\hline
\end{tabular}

nd: not determined, R: resistant, S: sensisitive

*results are mean of two separate experiments 
808 Table 4. Impact of human serum on Gram-negative bacteria (GNB) strains after none and 8093 hours contact time: examples of results for a sensitive strain (Pseudomonas group putida 810 VRBG 37.3) and a resistant strain (Chryseobacterium sp. (close to C. bovis) Pi18).

\begin{tabular}{ccccc}
\hline Dilution & $\begin{array}{c}\text { Chryseobacterium sp. } \\
\text { (close to C. bovis) Pi18 } \\
\text { (number of colonies) }\end{array}$ & $\begin{array}{c}\text { Pseudomonas putida } \\
\text { VRBG 37.3 } \\
\text { (number of colonies) }\end{array}$ & $\begin{array}{c}\text { Control sensitive } \\
\text { (number of colonies) }\end{array}$ & $\begin{array}{c}\text { Control } \\
\text { Resistant } \\
\text { (number of colonies) }\end{array}$ \\
\hline $\begin{array}{c}\text { At 0 hour } \\
10^{-1}\end{array}$ & $>1000$ & $>1000$ & & \\
$10^{-2}$ & $>1000$ & 141 & $>1000$ & $>1000$ \\
$10^{-3}$ & 354 & 6 & 42 & $>1000$ \\
$10^{-4}$ & 42 & 0 & 9 & 152 \\
At 3 & & & & 16 \\
$10^{-1}$ & $>1000$ & 0 & 0 & $>1000$ \\
$10^{-2}$ & $>1000$ & 0 & 0 & $>1000$ \\
$10^{-3}$ & $>1000$ & 0 & 0 & $>1000$ \\
$10^{-4}$ & 135 & 0 & 0 & 426 \\
\hline
\end{tabular}




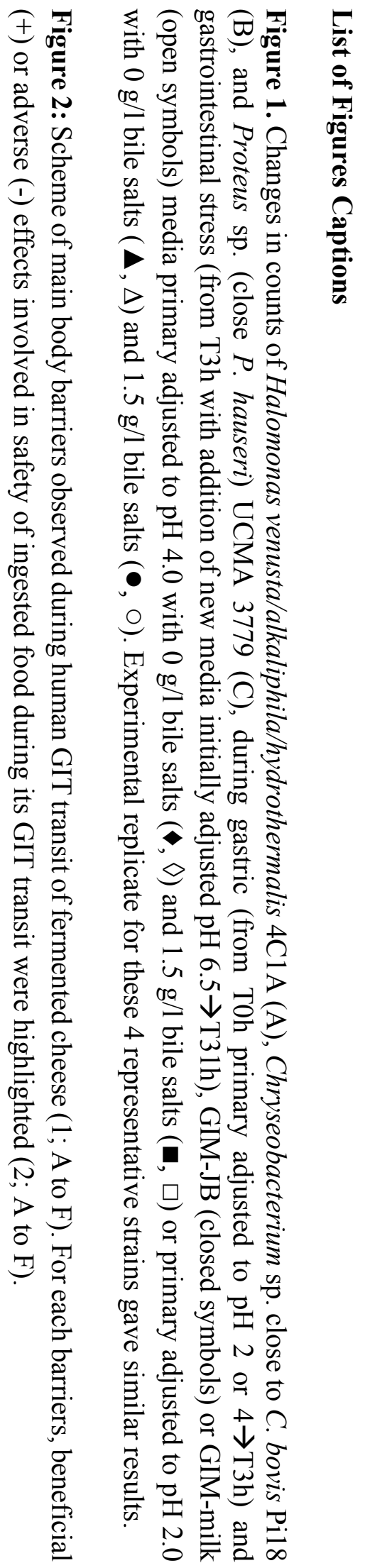



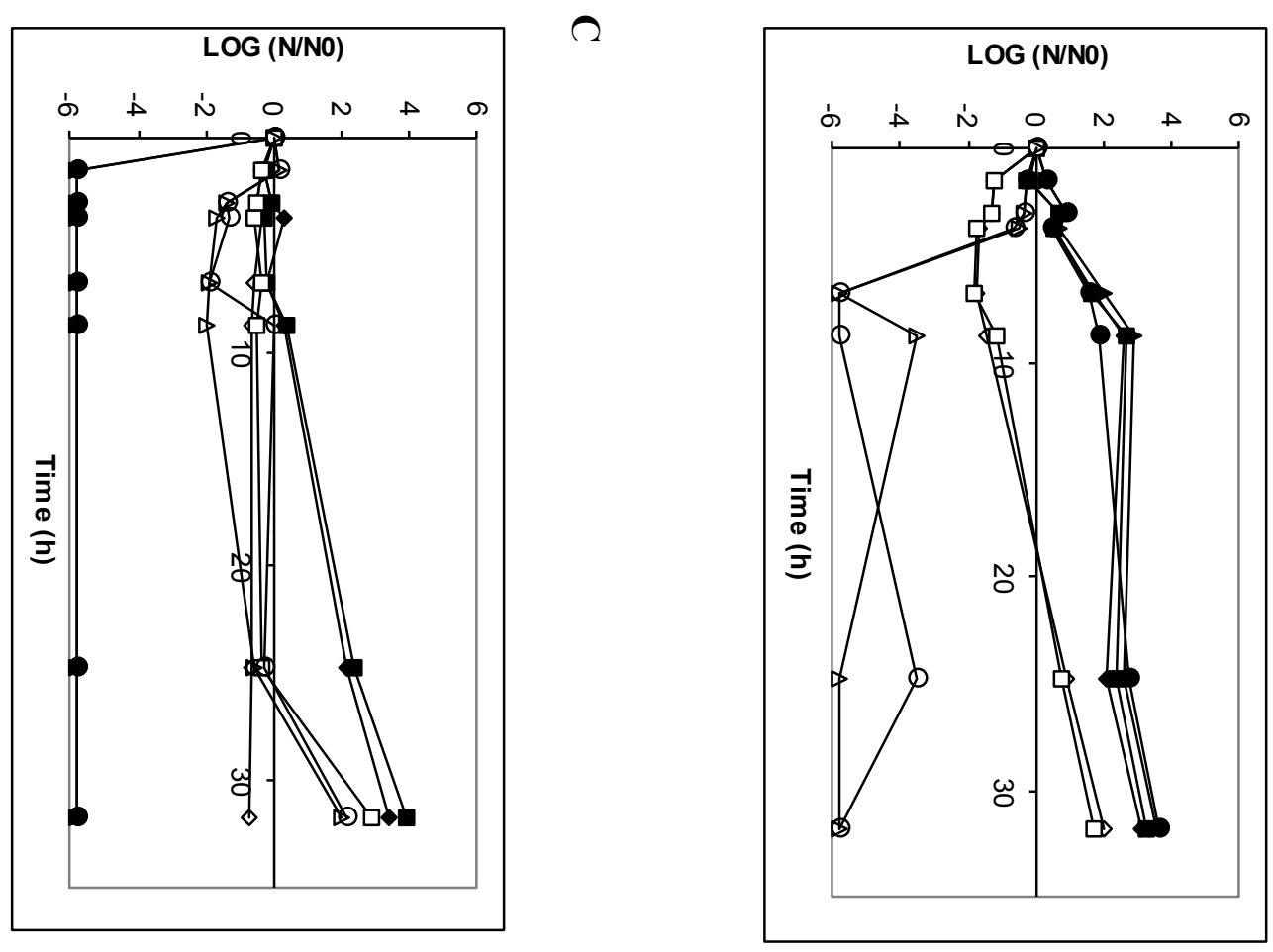

葛

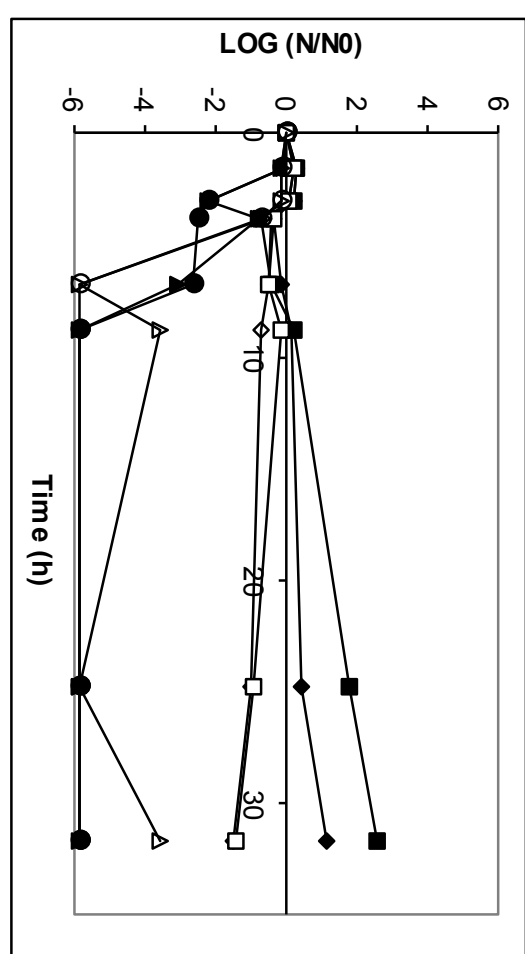

$\sigma$ 


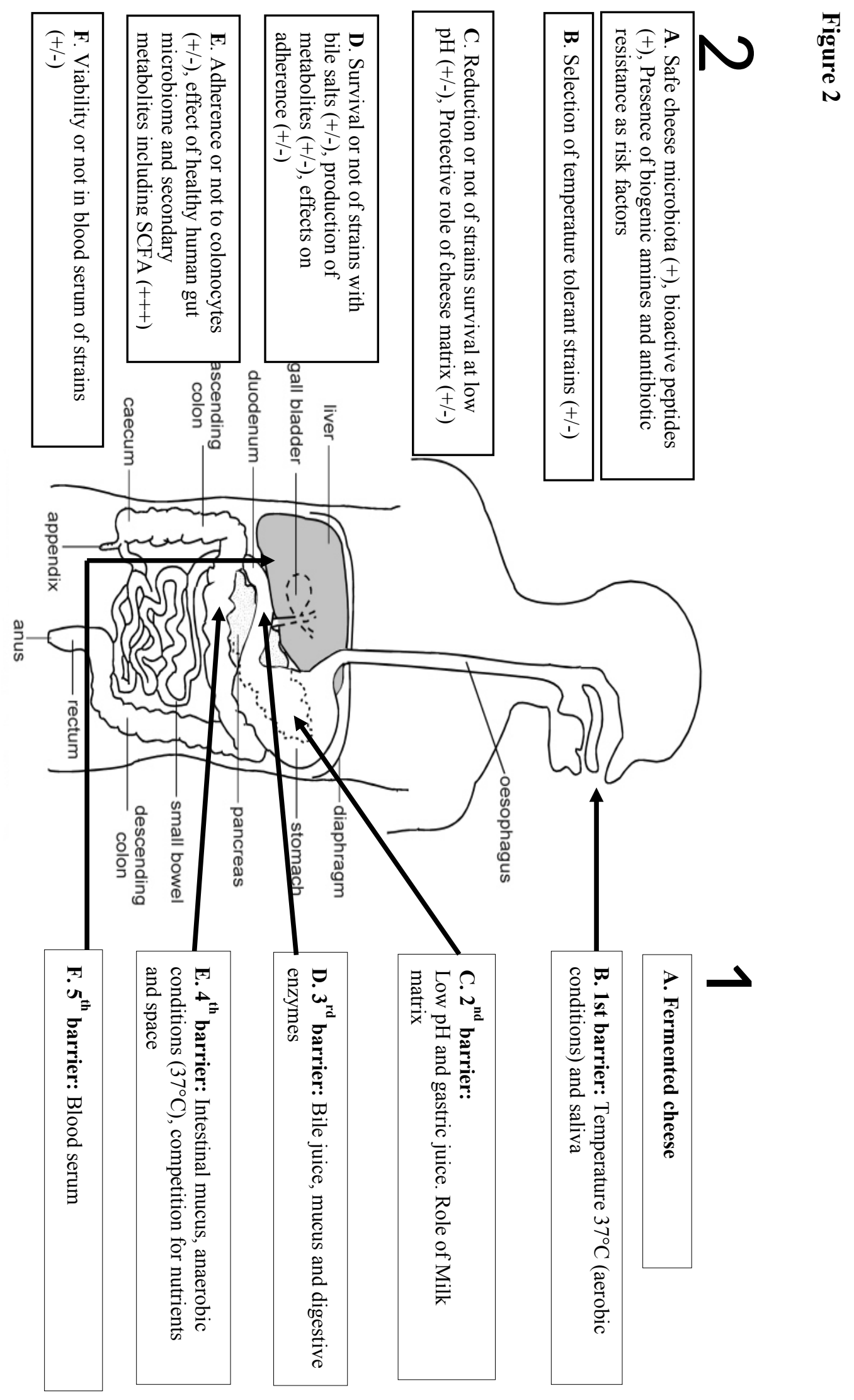





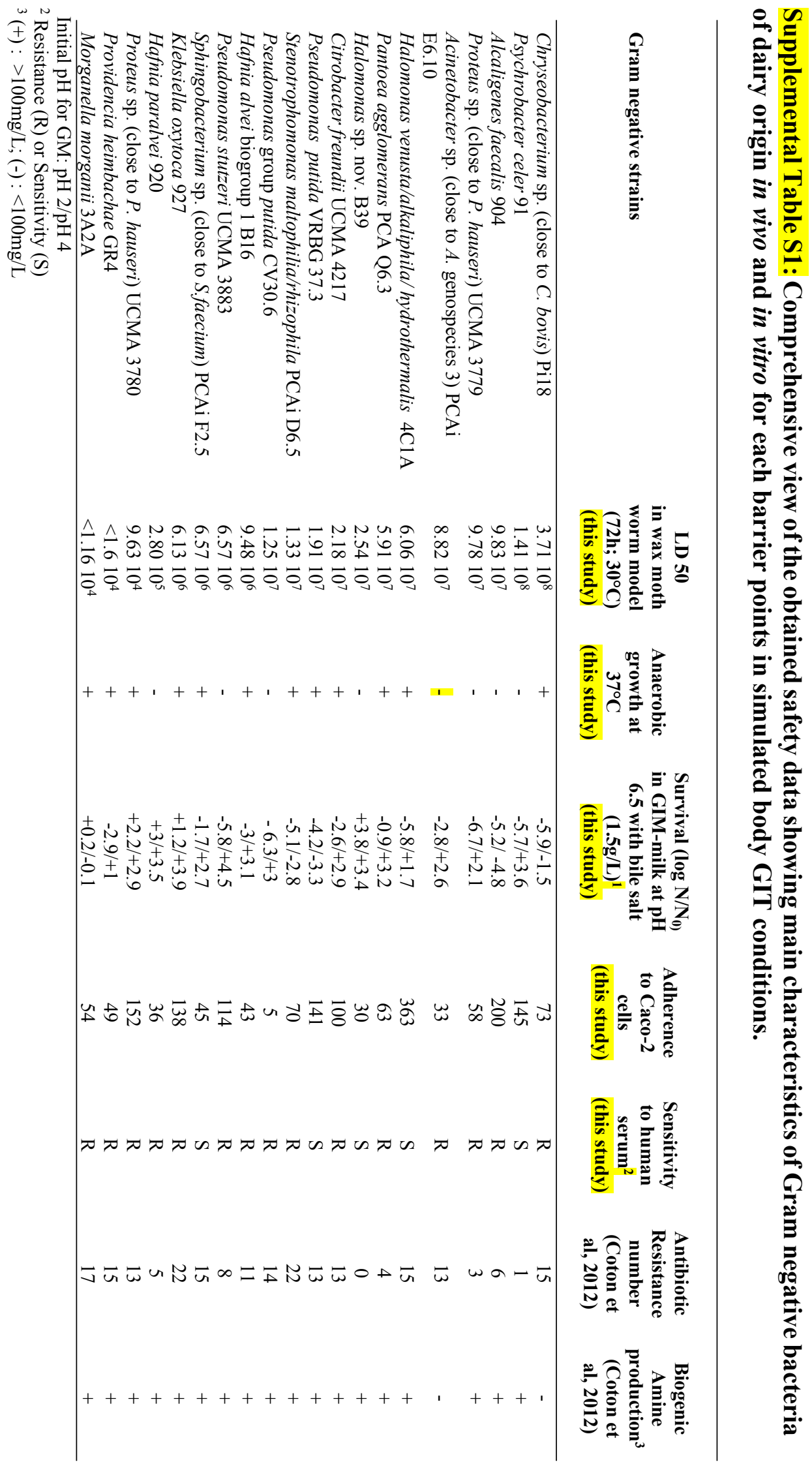




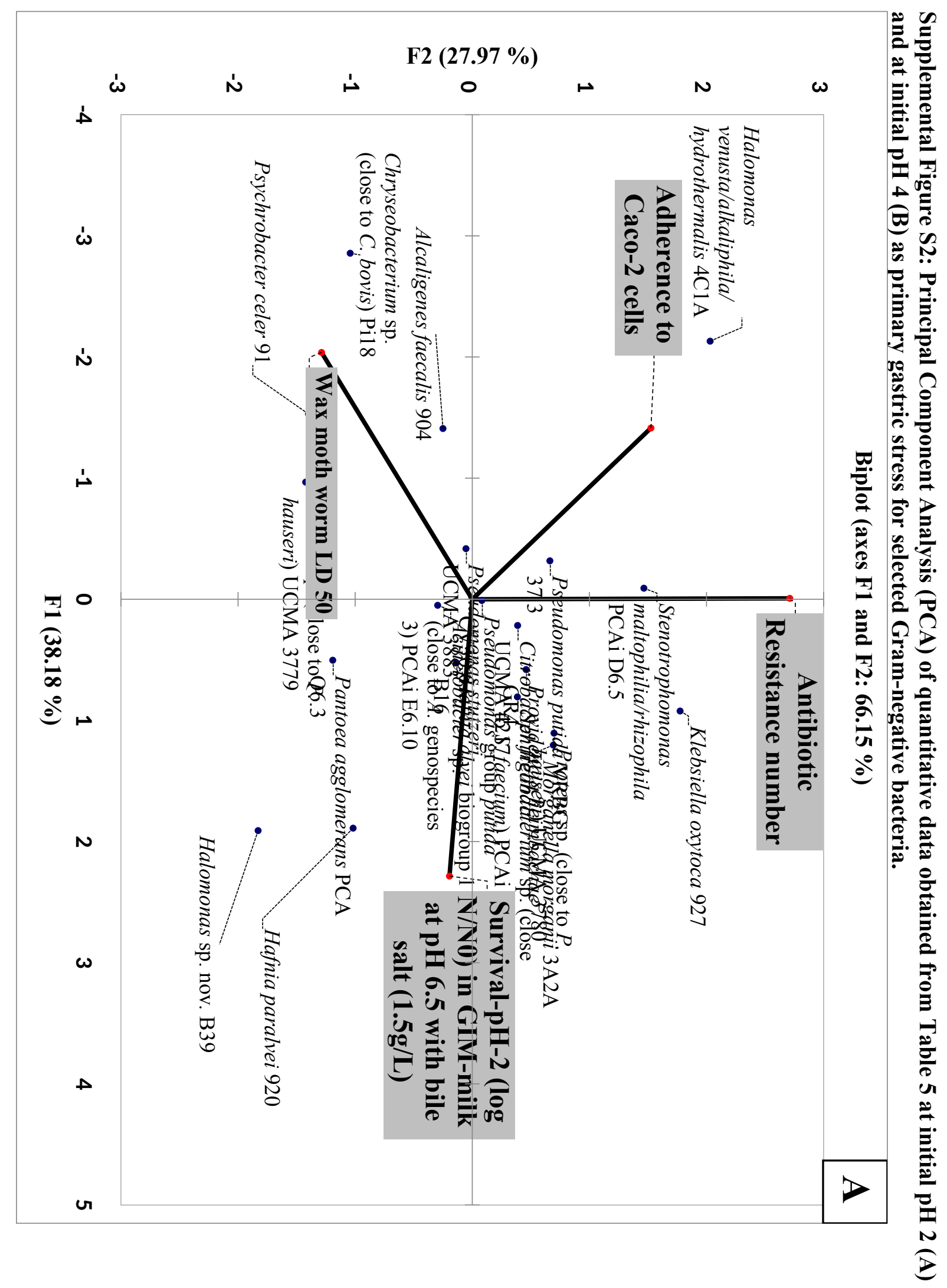




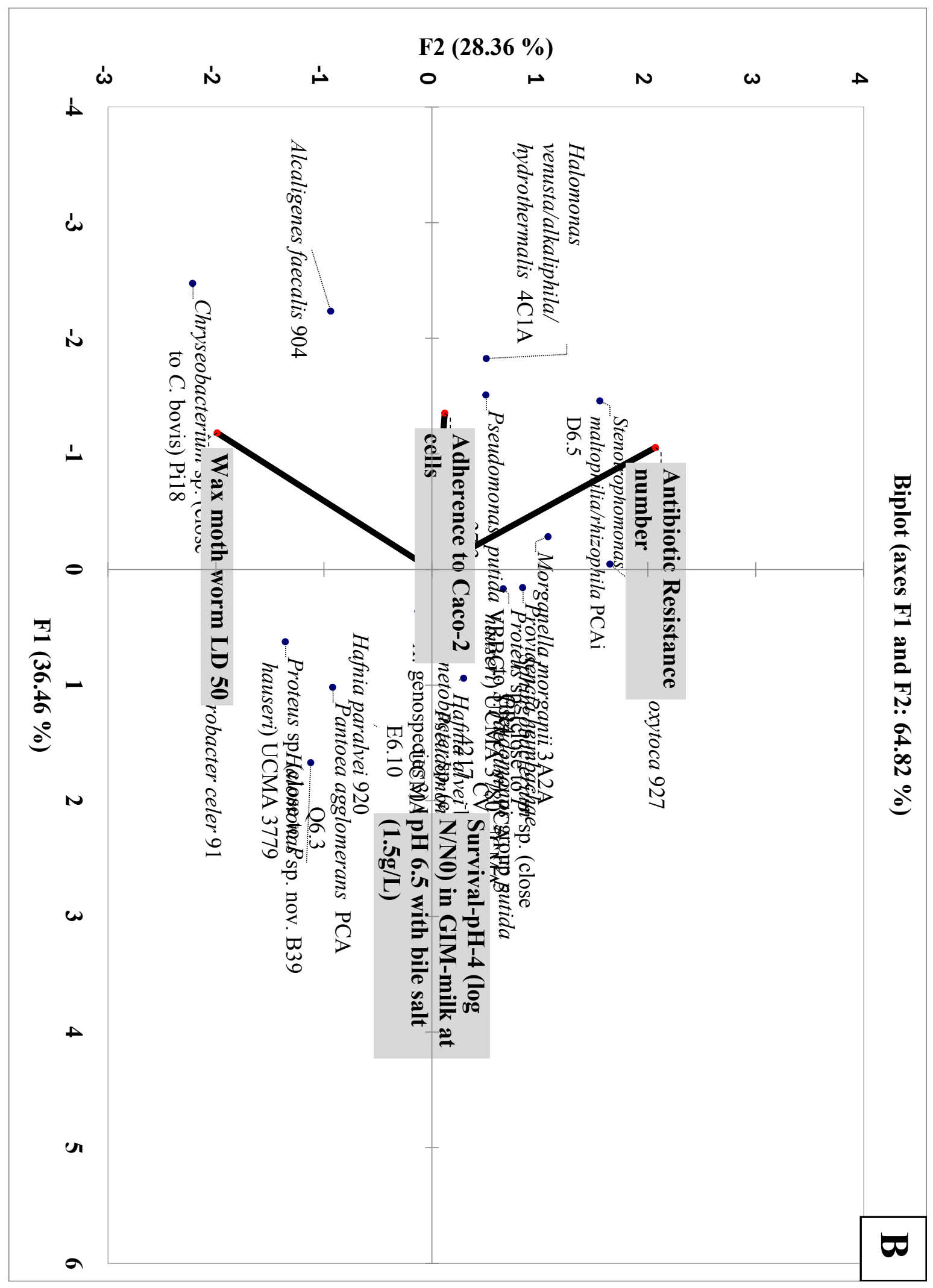




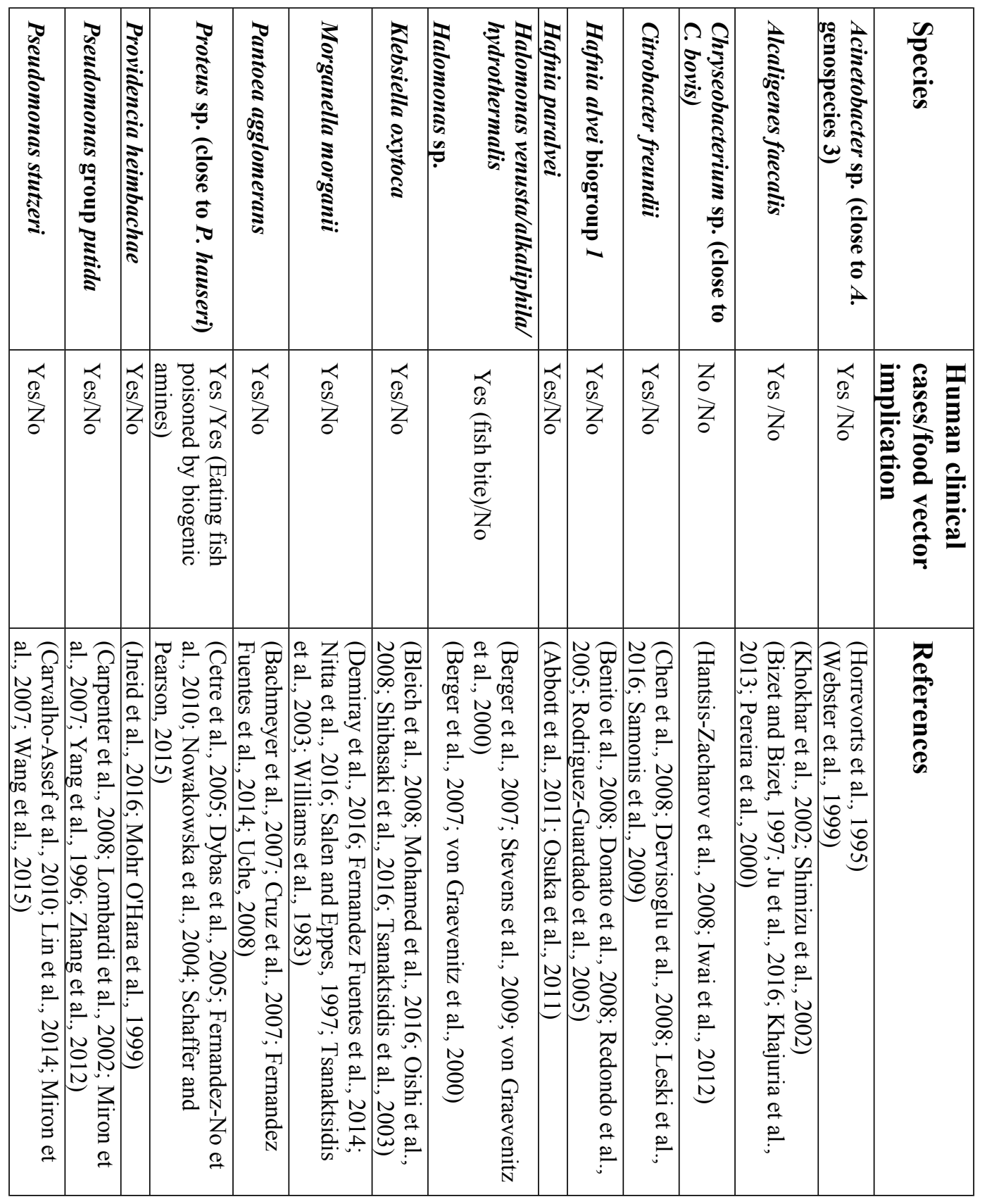




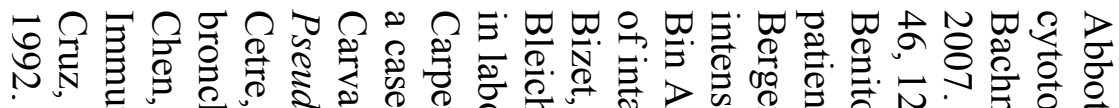

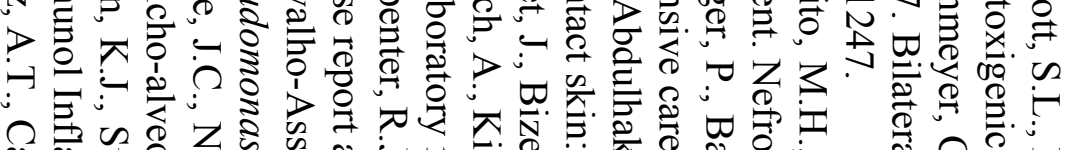

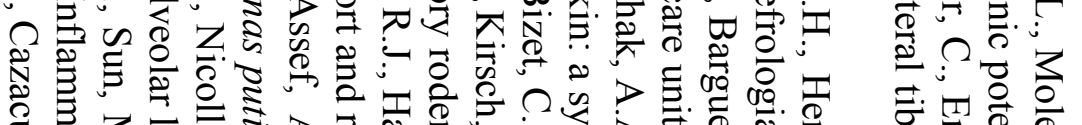

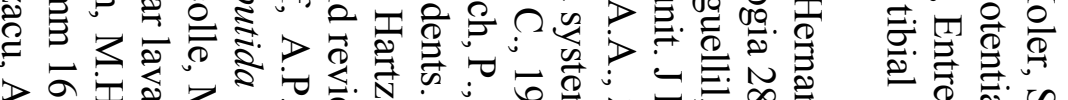

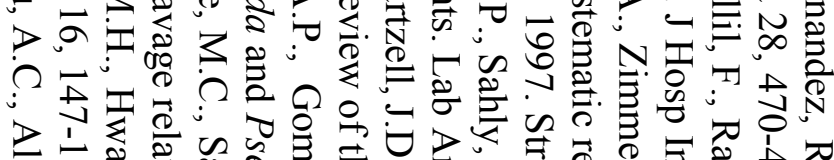

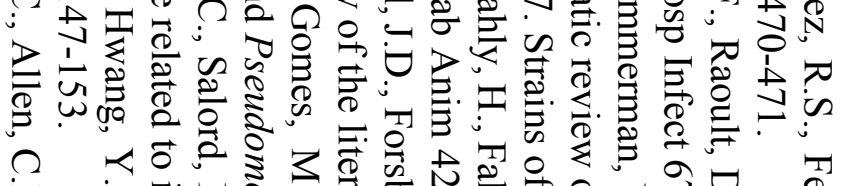

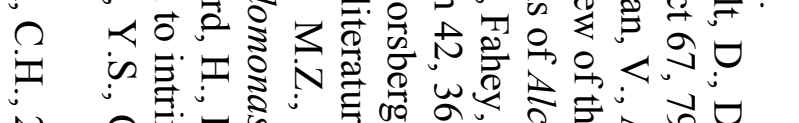

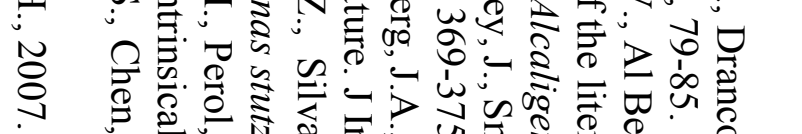

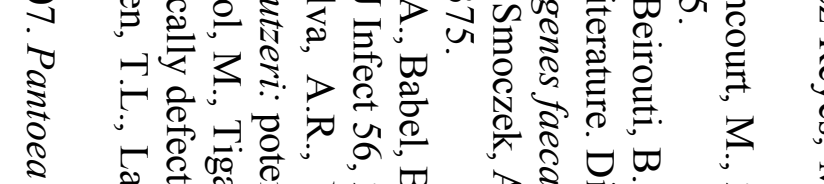

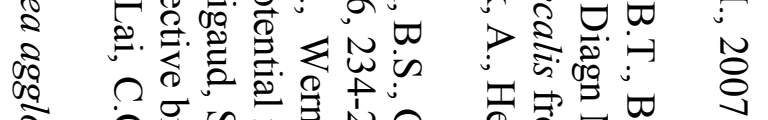

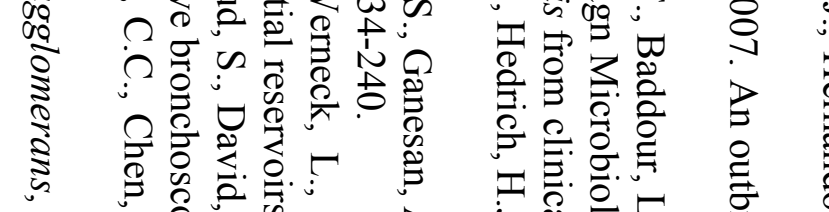

¿

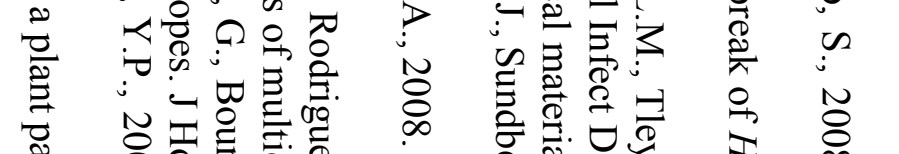

焉

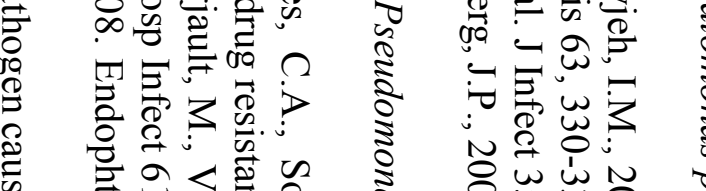

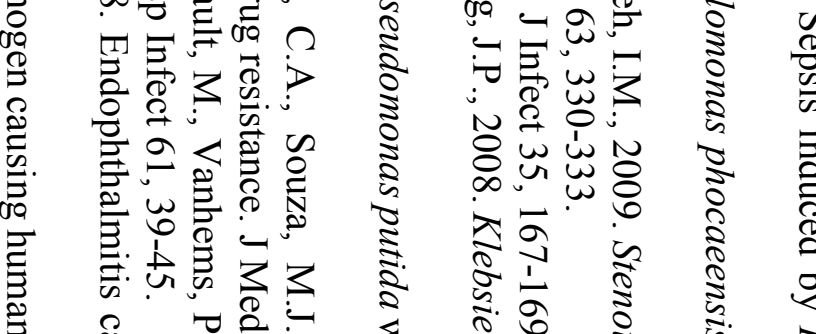

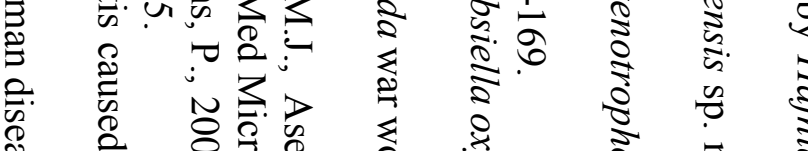

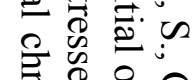

要号

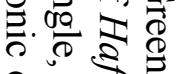

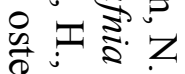

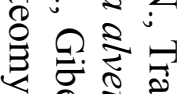

府

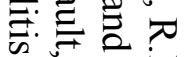

在了蛋

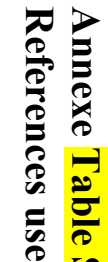

¿

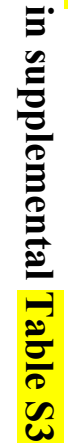

क

o Z :

$\tau$ कृष

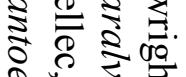

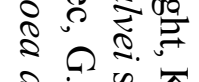

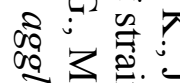

ऽ ज्ञ

จ

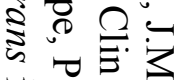

的讨

$\sim$ 응

둥

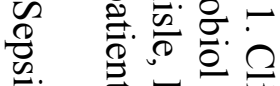

我

.

气.

- 育京岕

:

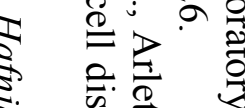

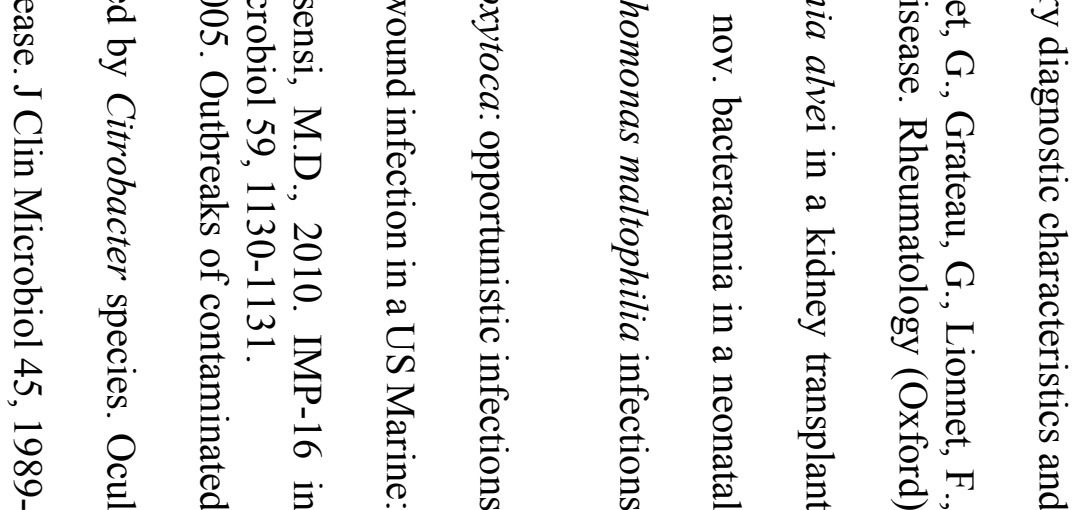

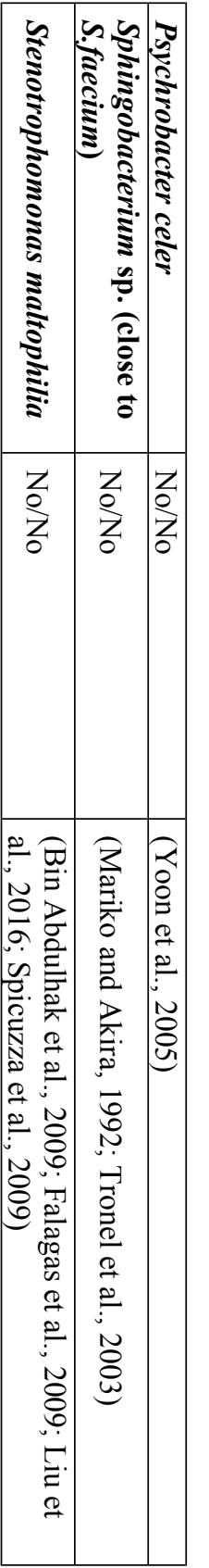




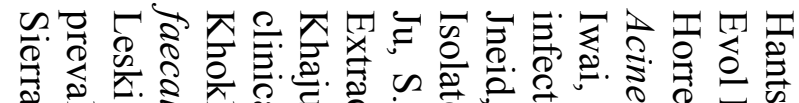

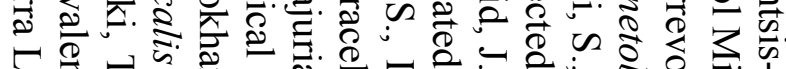

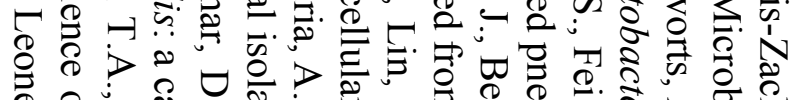

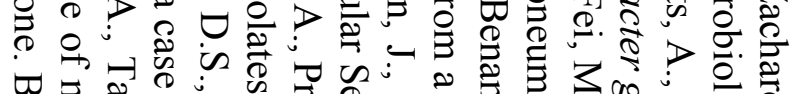

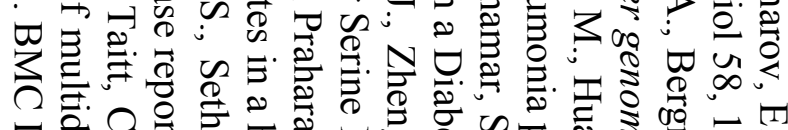

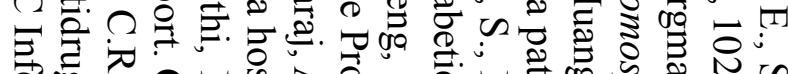

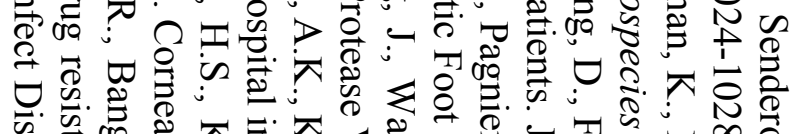

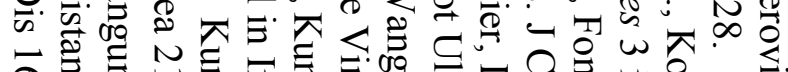

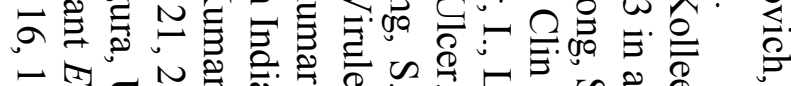

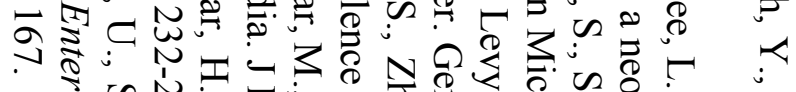

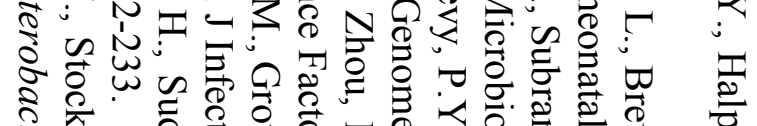

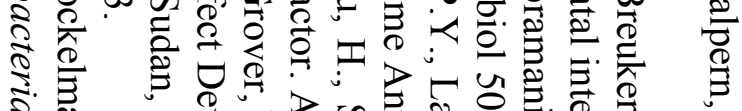

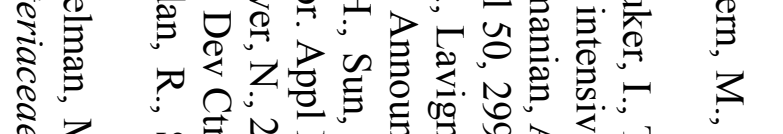

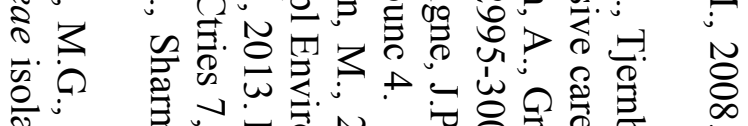

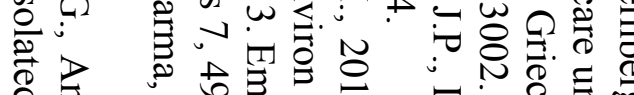

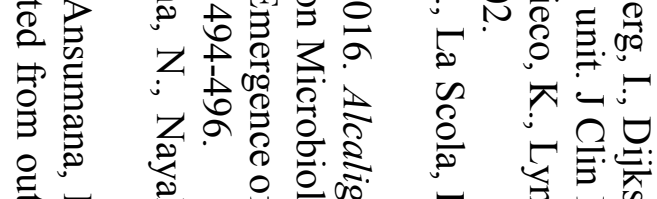

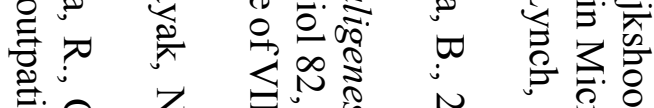

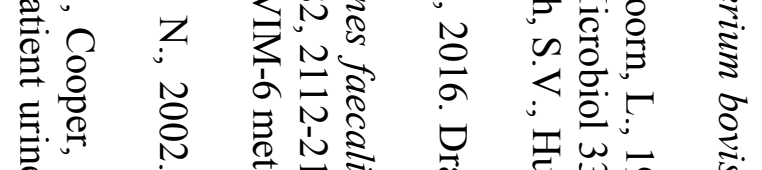

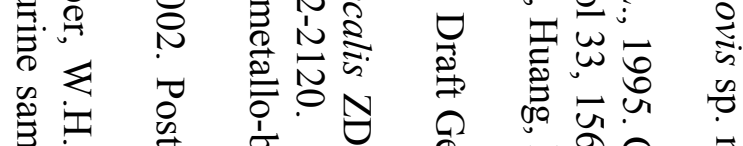

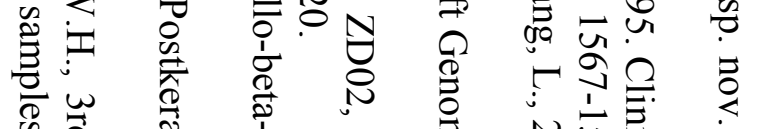

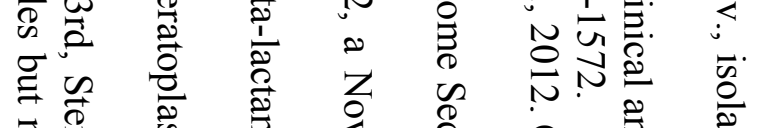

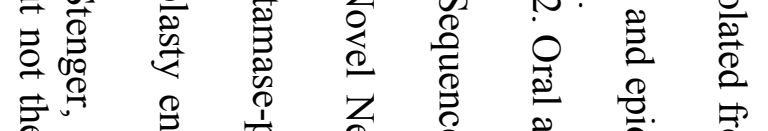

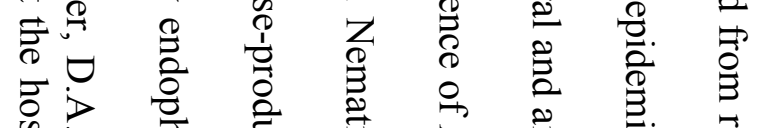

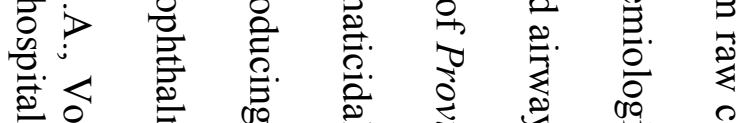

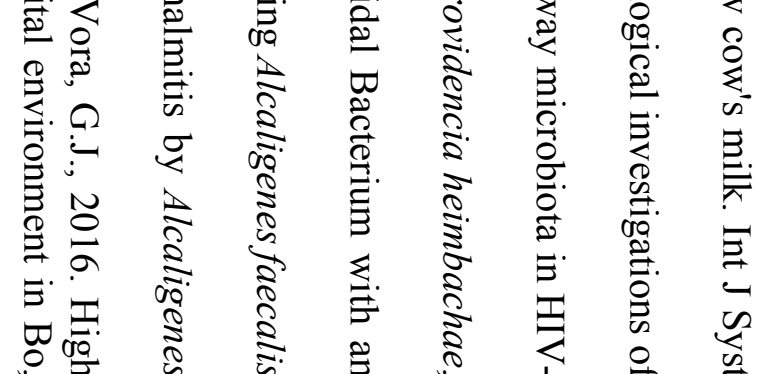

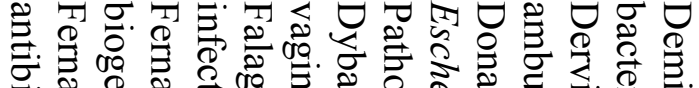
.

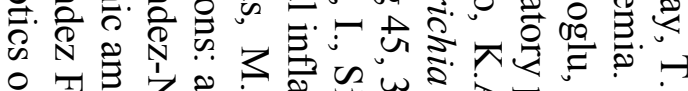

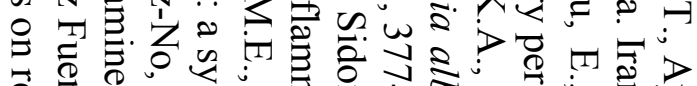

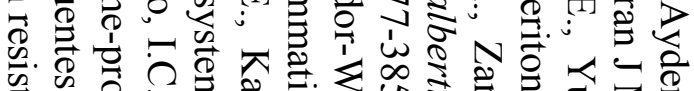

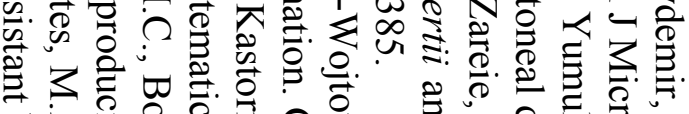

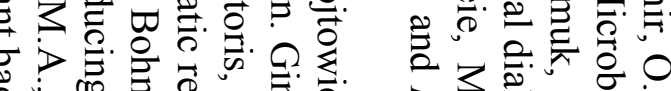

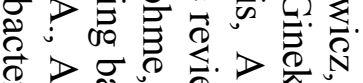

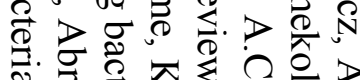

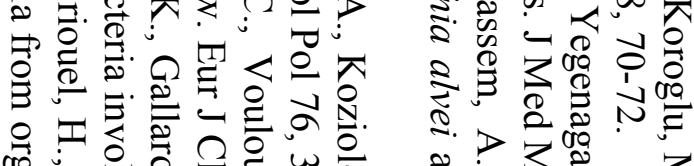

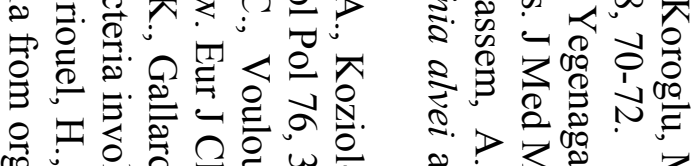

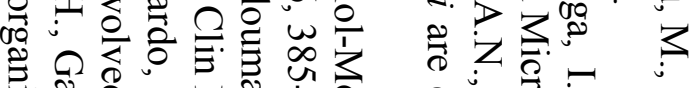

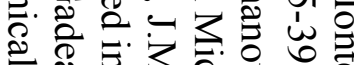

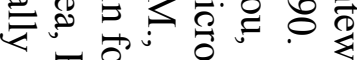

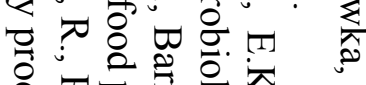

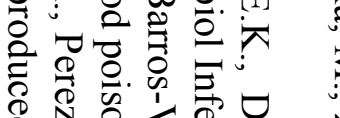

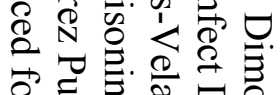

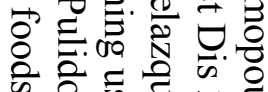

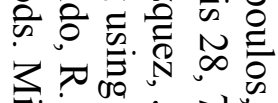
势, 일

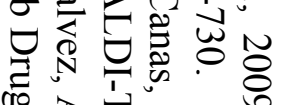

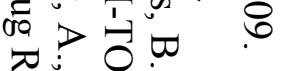

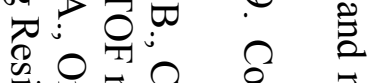

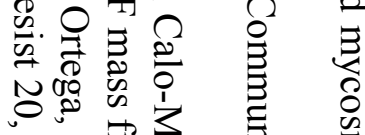

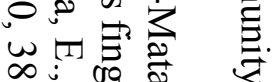
政

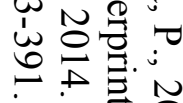

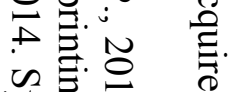

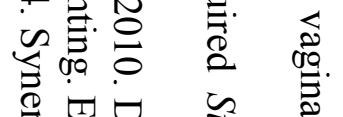

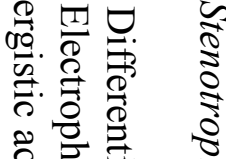
:

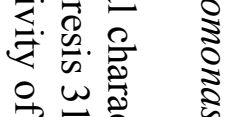

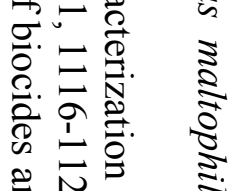
产牙要

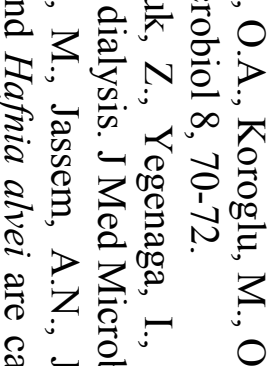

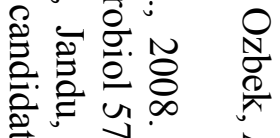

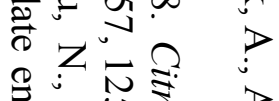

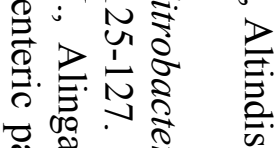

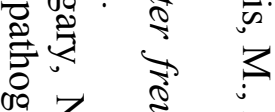
要娄

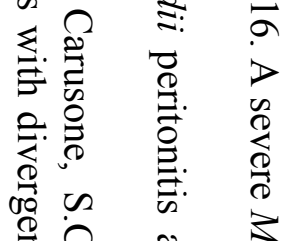
政

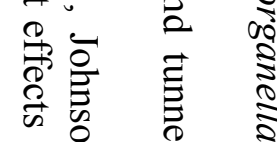
을 .

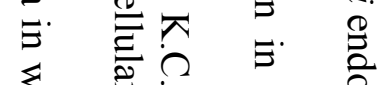

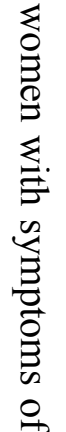
差 


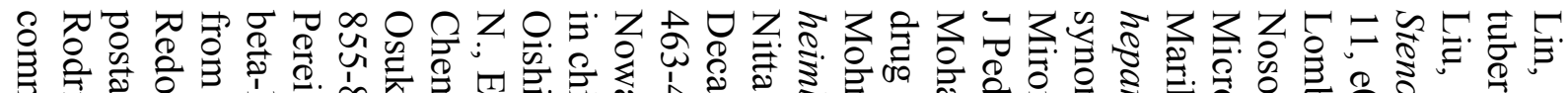

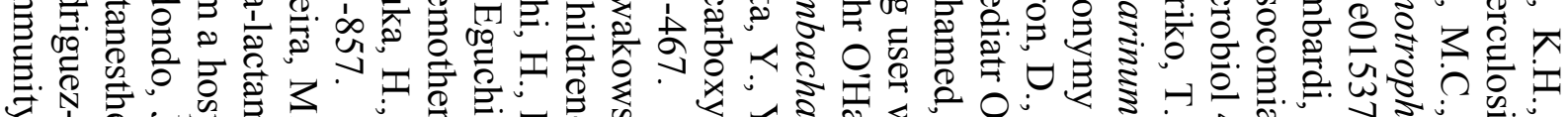

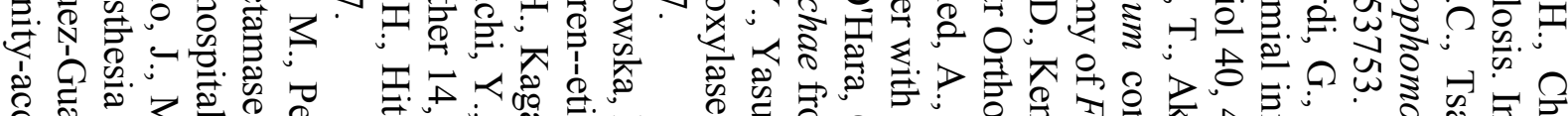

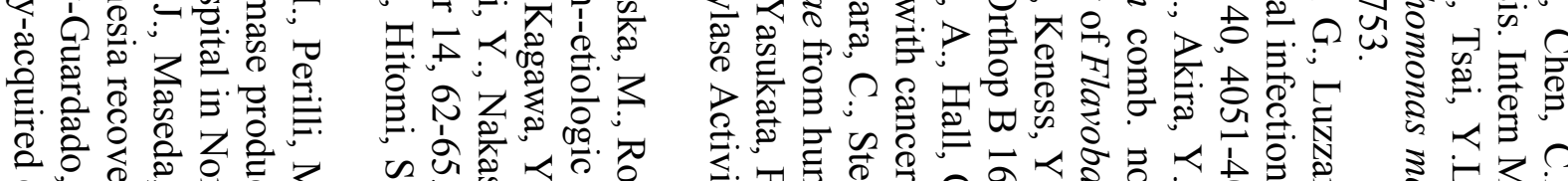

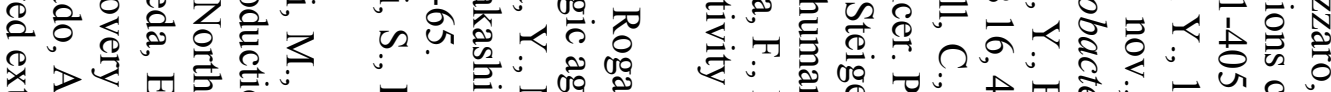

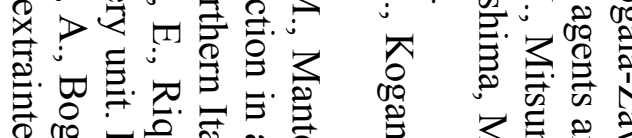

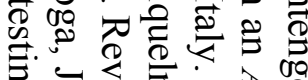

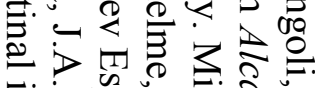

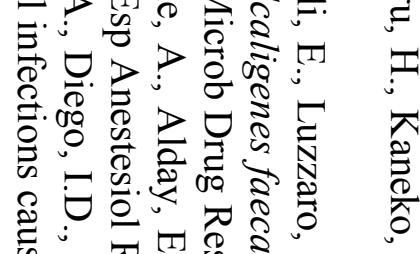

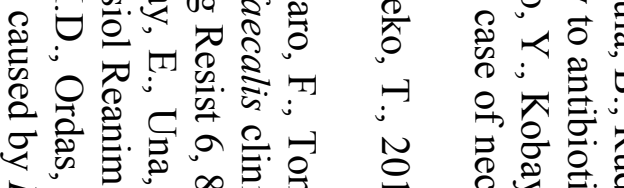

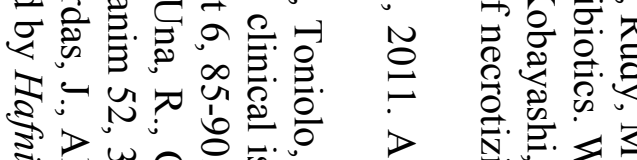

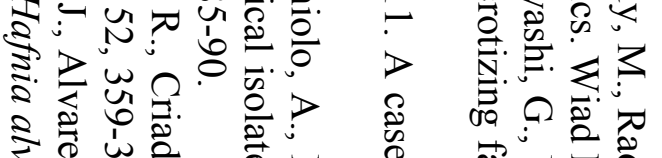

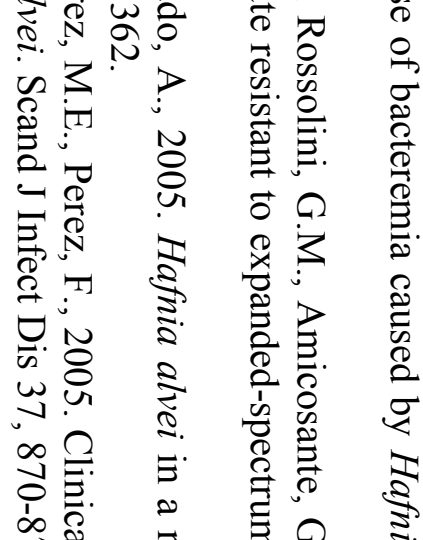
文

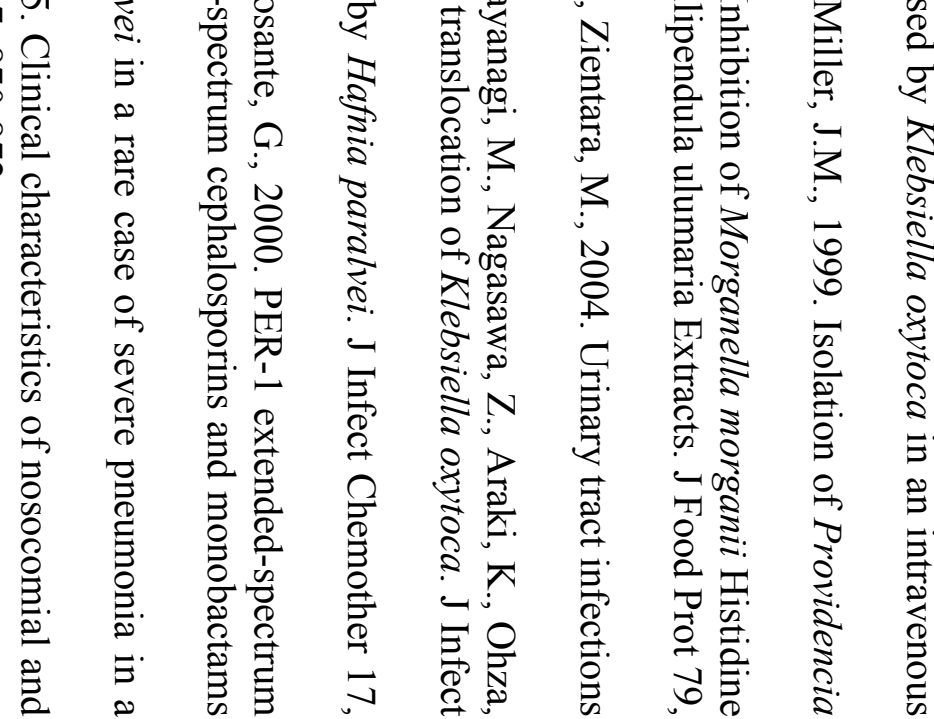

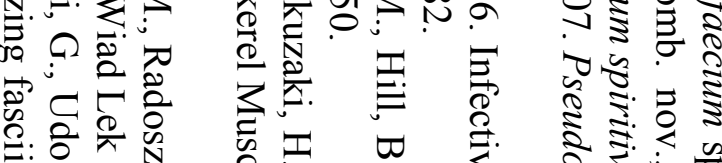

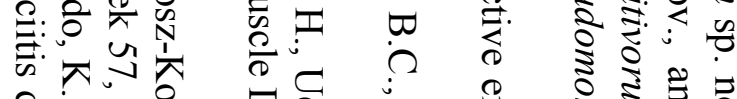

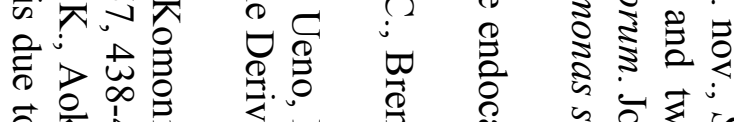

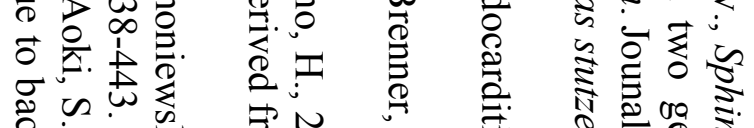

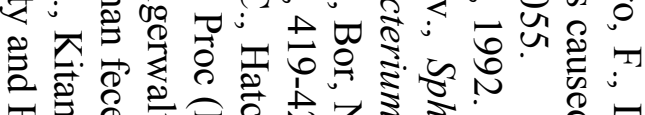

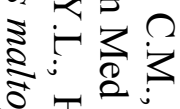
욜

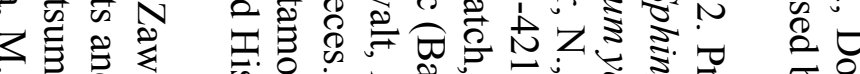

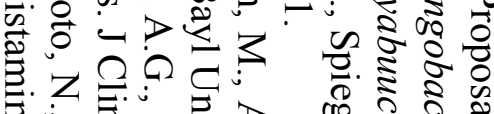
क人

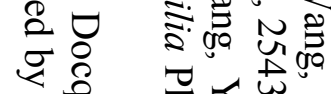

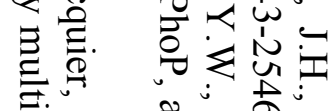
-

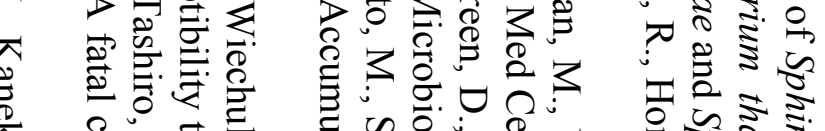

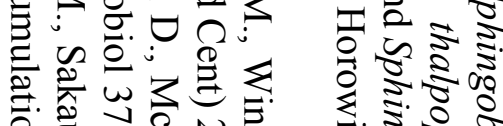

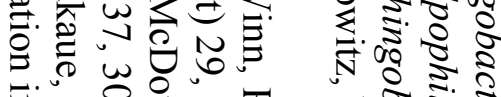
0
3
3

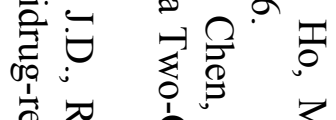

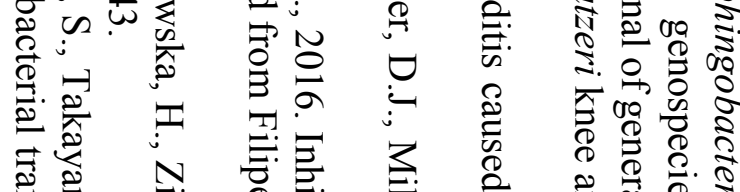

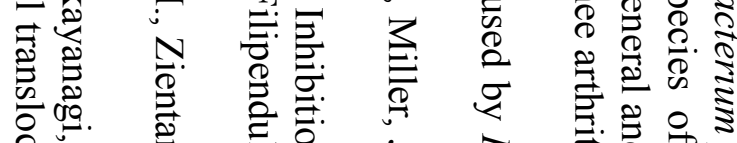
:

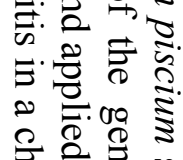

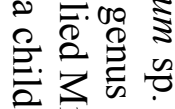

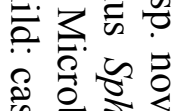
की

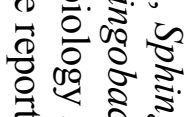

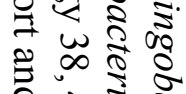

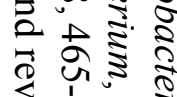

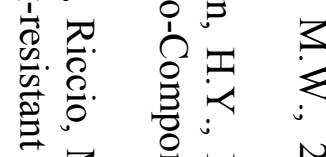

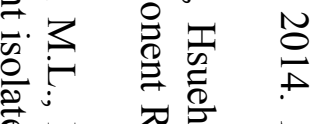

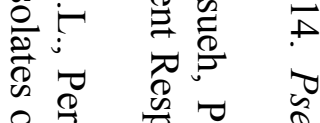

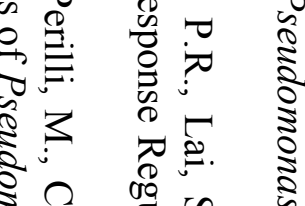

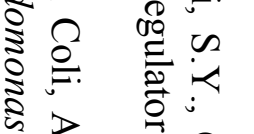

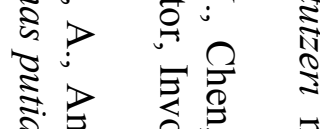

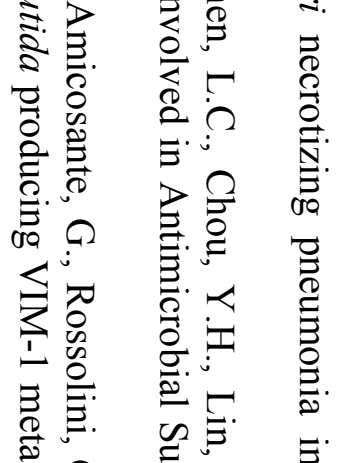

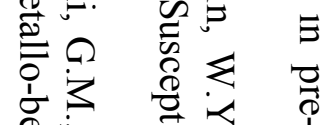

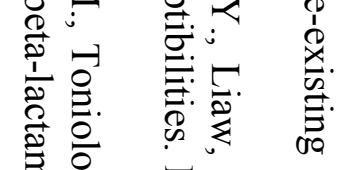
.

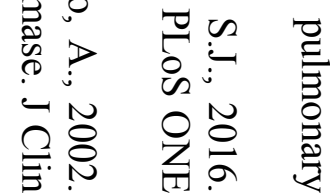




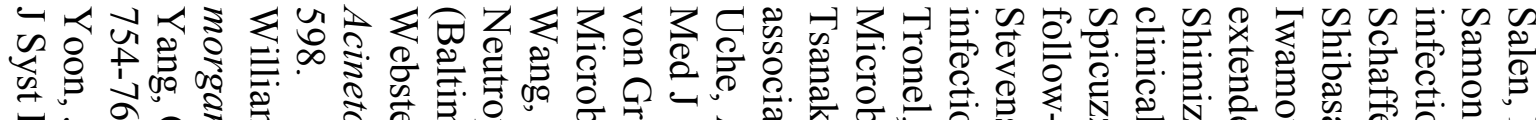

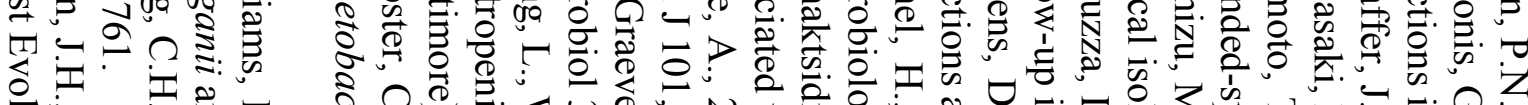

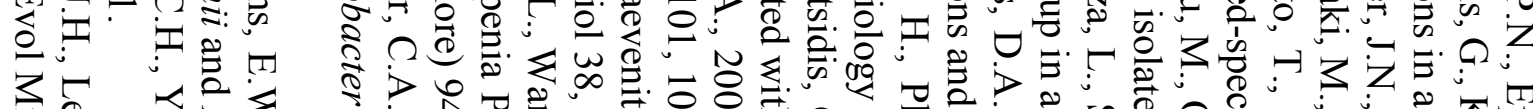

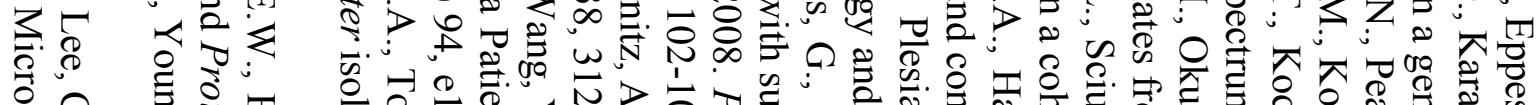

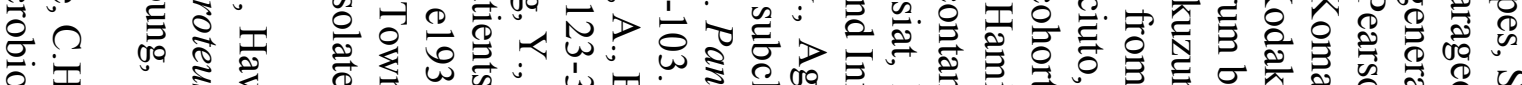

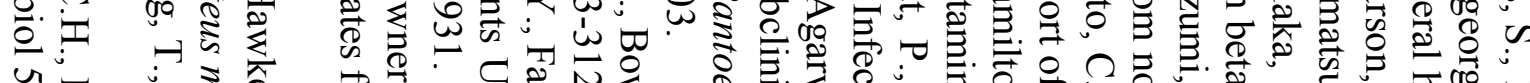

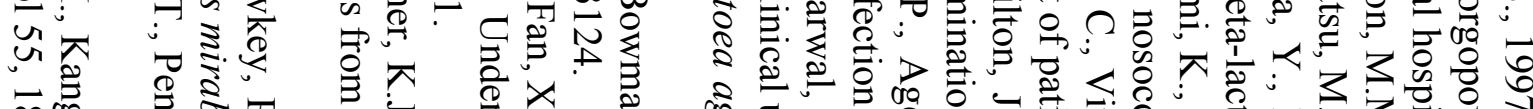

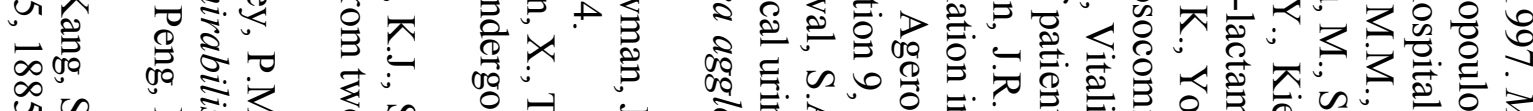

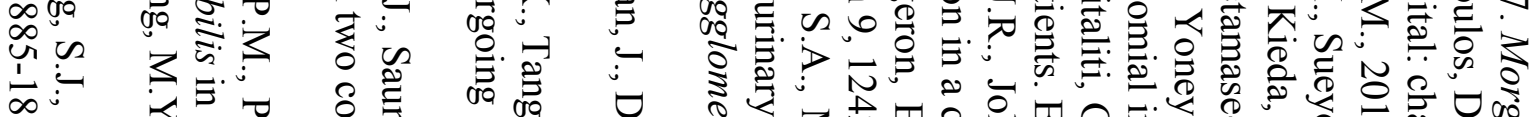

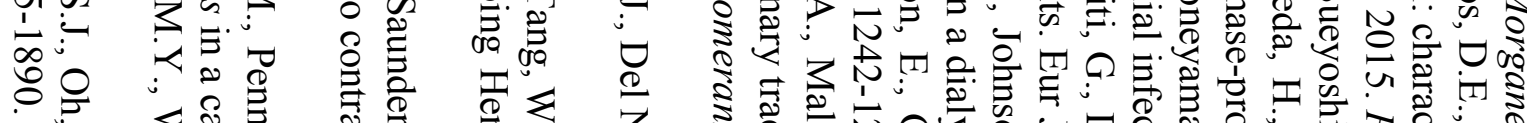

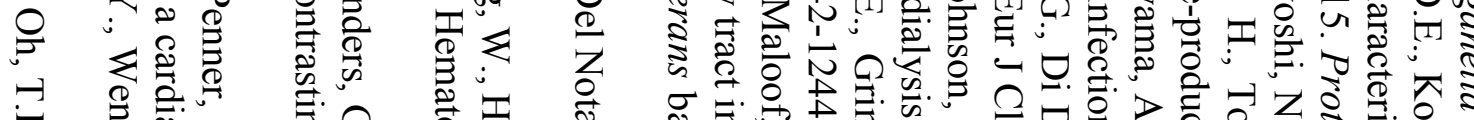

त्र

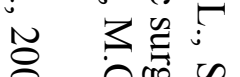
实

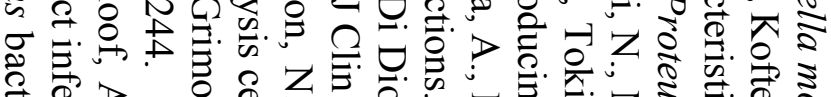

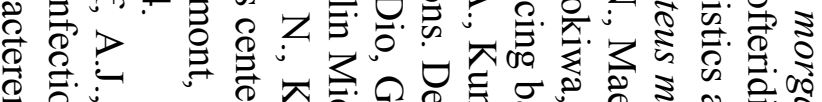

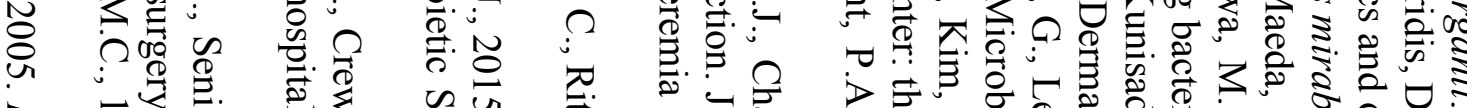

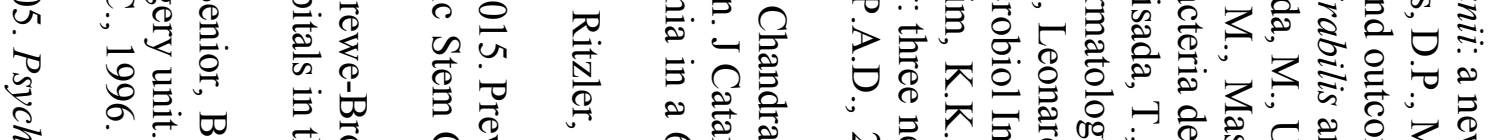

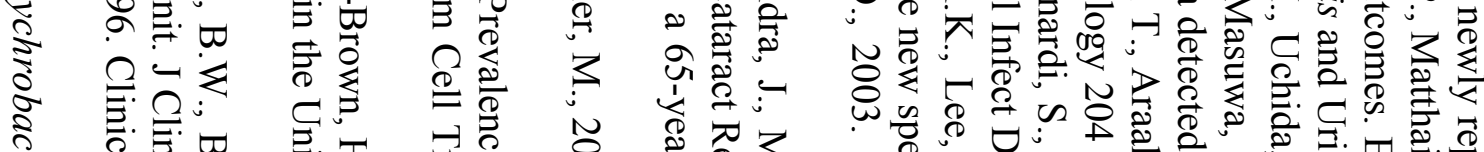

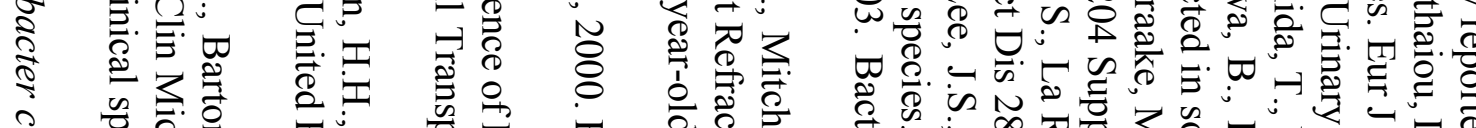

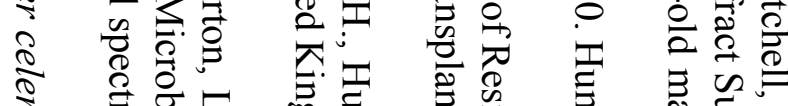

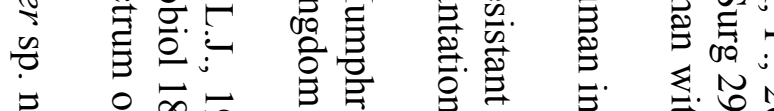

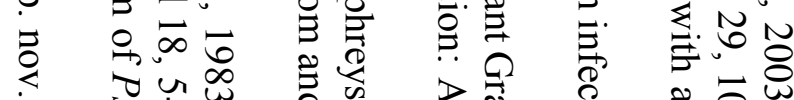

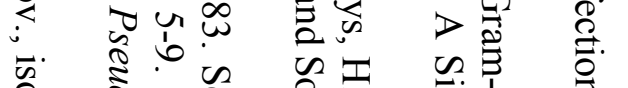

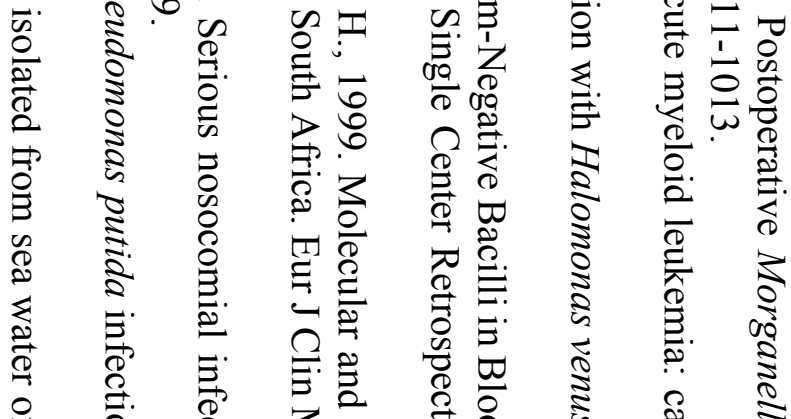

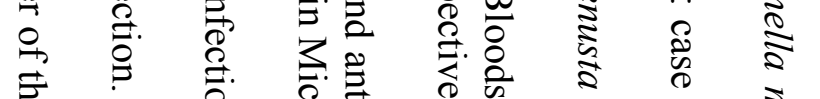

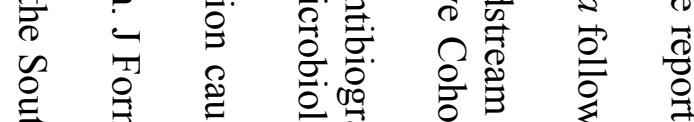

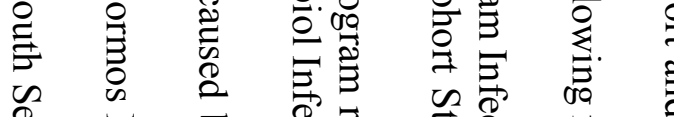

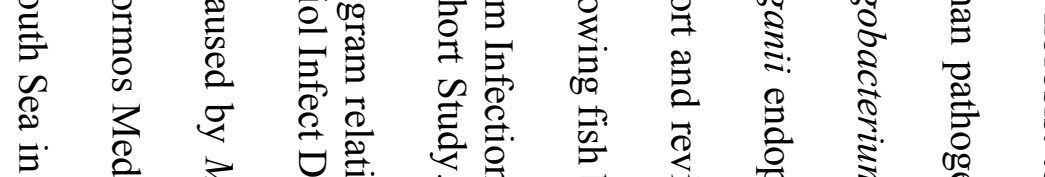

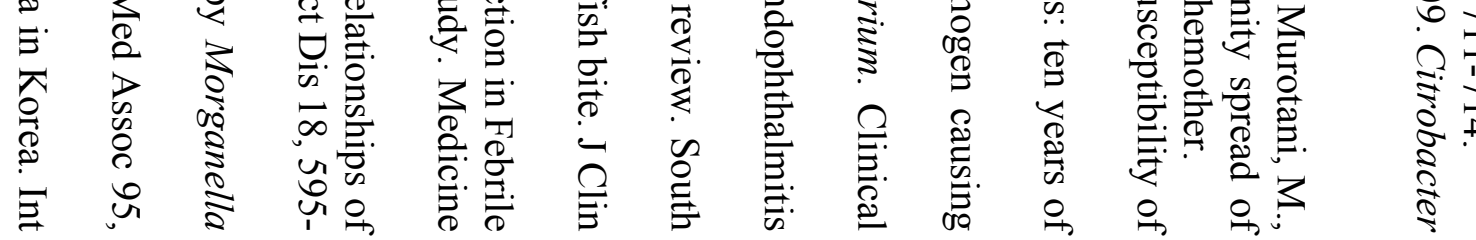




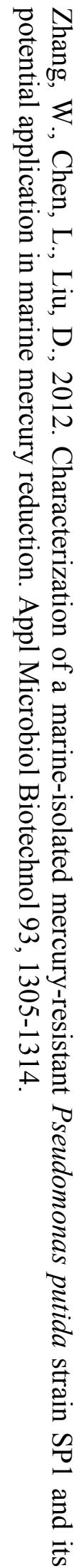

